\title{
Development of Environmentally Benign Organometallic Catalysis for Drug Discovery and Its Application
}

\author{
Mitsuhiro ARISAWA \\ Graduate School of Pharmaceutical Sciences, Hokkaido University; \\ Kita 12, Nishi 6, Kita-ku, Sapporo 060-0812, Japan. \\ Received May 1, 2007
}

\begin{abstract}
We have developed a novel organometallic catalysis and applied it to drug discovery. Two new catalysts were found, ruthenium hydride with a nitrogen-containing heterocyclic carbene (A) and an organopalladium catalyst supported on a sulfur-terminated semiconductor, gallium arsenide (001) (B). Both catalysts are environmentally benign, because A can yield indole derivatives with good atom economy, and B can catalyze the Mizoroki-Heck reaction more than 10 times with only trace amounts of leached palladium (ppb level). We also describe our synthetic study of nitrogen-containing heterocycles using ring-closing metathesis (RCM), such as chiral bicyclic lactams, azacycloundecenes, axially chiral macrolactams, 1,2-dihydroquinolines and indoles, including the development of silyl-enol ether ene metathesis, selective isomerization of terminal olefin, enamide metathesis and cycloisomerization and its application to the syntheis of 4 natural products, (-)-coniceine, $(S)$-pyrrolam A, angustureine, and fistulosin.
\end{abstract}

Key words organometallic; green chemistry; heterocycle; ruthenium; palladium

Organometallic catalyzed carbon-carbon bond formations are now essential in organic chemistry and have been widely applied to medicinal chemistry, process chemistry, etc. We developed a novel organometallic catalysis and their application to drug discovery and found two new catalysts, ruthenium hydride with a nitrogen-containing heterocyclic carbene (A) and an organopalladium catalyst supported on a sulfur-terminated semi-conductor, gallium arsenide (001) (B) (Chart 1). Both catalysts are environmentally benign, because $\mathbf{A}$ can yield indole derivatives with good atom economy, and $\mathbf{B}$ can catalyze the Mizoroki-Heck reaction more than 10 times with only trace amounts of leached palladium
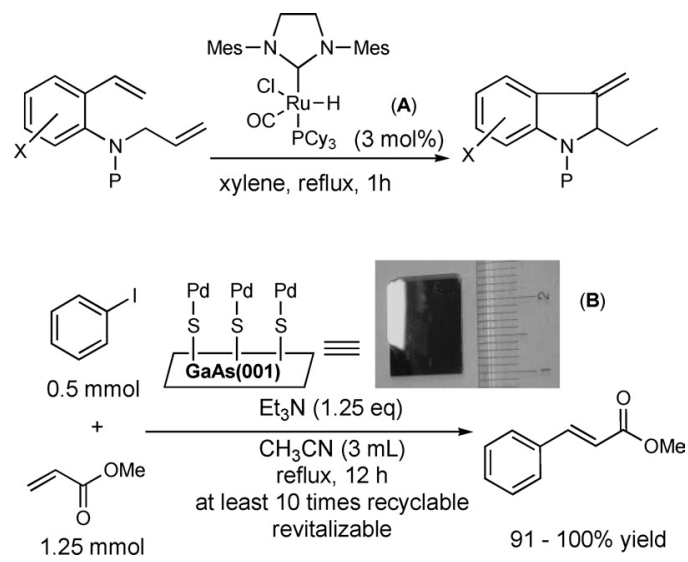

Chart 1. Our New Environmentally Benign Catalysts (ppb level). In this review, we describe the development of these catalysts and their application to the synthesis of bioactive natural products.

\section{Development of Synthetic Method for Nitrogen-Con-} taining Heterocycles Using Ruthenium Catalyst Including A

1.1. Ruthenium Carbene Catalysts Transition metalcatalyzed olefin metathesis is an important topic in current chemistry. In this field, ruthenium carbene catalysts have received much attention and are frequently used in the synthesis of biologically active natural products, because of their stability, functional group tolerance, easy handling and commercial availability. ${ }^{1-4)}$ Over the past decades, well-defined ruthenium catalysts have been developed and Grubbs et al. reported the first practical catalyst $(\mathbf{D}) .{ }^{5,6)}$ The recent introduction of catalysts $\left(\mathbf{E},{ }^{7-9)} \mathbf{G}^{10)}\right)$ bearing $N$-heterocyclic carbene (NHC) ligand has led to much higher reactivity (Fig. 1). For more than ten years, we have been exploring a synthetic methodology for nitrogen-containing heterocycles using these ruthenium carbene catalysts and applying them to the

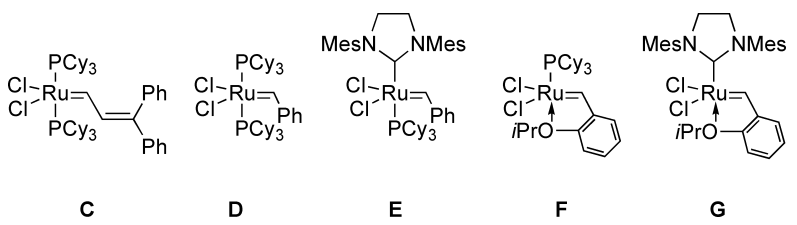

Fig. 1. Ruthenium Catalysts 
synthesis of biologically active natural products. ${ }^{11-30)}$

Here, we describe our synthetic study of nitrogen-containing heterocycles using ring-closing metathesis (RCM), such as chiral bicyclic lactams, azacycloundecenes, axially chiral macrolactams, 1,2-dihydroquinolines and indoles, including the development of silyl-enol ether ene metathesis and selective isomerization of terminal olefin, and its application to the synthesis of the natural products, (-)-coniceine, $(S)$ pyrrolam A and angustureine.

1.1.1. Chiral Bicyclic Lactams, Synthesis of (-)-Coniceine and $(S)$-Pyrrolam $\mathrm{A}^{11,15)}$ : Biologically active alkaloids having an azabicyclic framework are abundant in nature. The pyrroloazocine, pyrroloazepine, quinolizidine, and indolizidine alkaloids fall into this category and have attracted considerable attention from the synthetic viewpoint due to their biological activity. ${ }^{31-35)}$ As a part of our program $^{12,36-40)}$ directed toward the synthesis of manzamine A (Fig. 2), RCM strategy for the construction of optically active 1,2-cyclooctanopyrrolidine corresponding to the $\mathrm{CD}$ ring in manzamine A and related azabicycles was investigated. We studied RCM of chiral dienes which are readily available from L-proline.

The overall procedure consisted of the RCM reaction of chiral dienes $(\mathbf{1}-\mathbf{5})$ in the presence of catalyst $(\mathbf{C}, \mathbf{D})$ to form the corresponding bicyclic lactam (6-9) (Table 1). Dienes $\mathbf{1}-\mathbf{5}$ were prepared from L-proline in good yield and subjected to RCM. RCM reaction of these dienes is quite interesting, since the expected azabicyclic compounds offer tremendous utility as reaction intermediates in organic synthesis. When 1 was treated with $5 \mathrm{~mol} \%$ of catalyst $\mathbf{C}$ in degassed benzene $(20 \mathrm{~mm})$ at room temperature for $3 \mathrm{~d}$, indolizidine 6 was obtained in 93\% yield (entry 1). The reaction of $\mathbf{1}$ using catalyst $\mathbf{D}$, on the other hand, proceeded more rapidly and 6 was obtained in 66\% yield (entry 2). Cyclization of $\mathbf{2}$ to 7 also proceeded more rapidly using catalyst D and 7 was obtained in $73 \%$ yield, respectively (entry 3 ).

Initial attempts to cyclize diene $\mathbf{3}$ to 5 membered lactam $\mathbf{8}$ under similar conditions ( $20 \mathrm{~mm}$, room temperature) using $10 \mathrm{~mol} \%$ of $\mathbf{C}$ in benzene were unsuccessful, perhaps due to the formation of stable chelated species. Accordingly, we carried out RCM of $\mathbf{4}$ and the expected cyclization to 8 was found to occur under a forced condition $\left(50^{\circ} \mathrm{C}\right)$ to give $(S)$ pyrrolam A (8) in 30\% yield (entry 4 ). The low yield observed in the formation of $\mathbf{8}$ appeared to be due to the instability of the product under reaction conditions.

Our next stage was to explore the feasibility of construc-

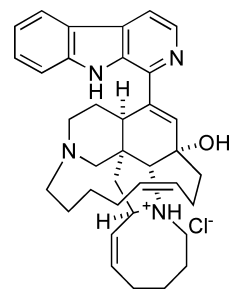

Fig. 2. Structure of Manzamine A

Table 1. Construction of Chiral Cycloalkanopyrrolidines Using RCM

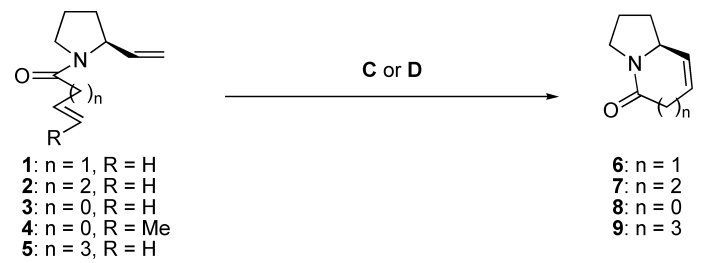

\begin{tabular}{|c|c|c|c|c|c|c|c|}
\hline Entry & Diene & $\begin{array}{l}\text { Ru catalyst } \\
(\mathrm{mol} \%)\end{array}$ & Solvent & $\begin{array}{l}\text { Conc. } \\
(\mathrm{mm})\end{array}$ & $\begin{array}{l}\text { Temp. } \\
\left({ }^{\circ} \mathrm{C}\right)\end{array}$ & Time & $\begin{array}{c}\text { Yield product } \\
(\%)\end{array}$ \\
\hline 1 & 1 & $C(5)$ & Benzene & 20 & $\mathrm{rt}$ & $3 d$ & 6,93 \\
\hline 2 & 1 & D (5) & Benzene & 20 & $\mathrm{rt}$ & $18 \mathrm{~h}$ & 6,66 \\
\hline 3 & 2 & D (5) & Benzene & 20 & $\mathrm{rt}$ & $4 d$ & 7,73 \\
\hline 4 & 4 & D (5) & Benzene & 20 & 50 & $3 \mathrm{~h}$ & 8,30 \\
\hline 5 & 5 & D (25) & $\mathrm{CH}_{2} \mathrm{Cl}_{2}$ & 2 & 50 & $20 \mathrm{~h}$ & 9,45 \\
\hline
\end{tabular}

Mitsuhiro Arisawa was born in 1971 in Osaka. He received his bachelor's degree (Prof. Mikio Yamazaki) in 1994 and his master's degree in 1996 (Prof. Masako Nakagawa) from the Faculty of Pharmaceutical Sciences at Chiba University, Japan. He received his Ph.D. degree from the Graduate School of Pharmaceutical Sciences of Osaka University, Japan, in 1999 (Prof. Yasuyuki Kita). He joined the Faculty of Pharmaceutical Sciences at Chiba University, Japan, in 1999 as an assistant professor. From 2002 to 2004, he spent 16 months as a visiting scholar at Harvard University, U.S.A. (Prof. Matthew D. Shair). Since 2005, he has been an associate professor of the Graduate School of Pharmaceutical Sciences at Hokkaido University, Japan. His current research interest is in organic chemistry toward the development of medicinal chemistry. In 2007, he received the Pharmaceutical Society of Japan Award for a Young Chemist.

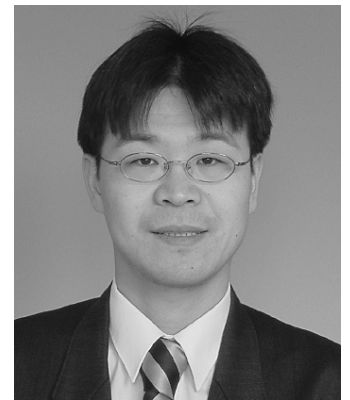

Mitsuhiro Arisawa 
tion of a medium ring such as $\mathbf{9}$, which corresponds to the $\mathrm{CD}$ ring in manzamine A. Although in many cases acyclic ring closure did not proceed effectively in the 8 membered series, several groups ${ }^{41-45}$ ) have succeeded in obtaining an 8 membered ring system by RCM methodology. In our preliminary investigation, the cyclization of a diene, $\mathbf{5}$, to an 8 membered ring system was not successful. However, heating the reaction of $\mathbf{5}$ and $\mathbf{D}(25 \mathrm{~mol} \%)$ at $50{ }^{\circ} \mathrm{C}$ gave $\mathbf{9}$ in $45 \%$ yield (entry 5). Lactam 6 was successfully converted to (-)coniceine (11), the simplest indolizidine alkaloid via stepwise reductions as shown in Chart 2.

1.1.2. Azacycloundecenes, toward Manzamine $\mathrm{C}$, and Their Oxoanalogues ${ }^{13)}$ : Manzamine C (12, Fig. 2) is the simplest congener and bears an unprecedented azacycloundecene ring. ${ }^{46)}$ The total synthesis of $\mathbf{1 2}$ was first achieved by Hino's group ${ }^{47,48)}$ and afterward by Gerlachs' group ${ }^{49)}$ and Langlois' group ${ }^{50)}$ using their own original methods. In our synthesis of $\mathbf{1 2}$ and trans-manzamine C (13), cis and trans azacycloundecenes were key intermediates, and were prepared by conventional methods. We have also successfully developed an efficient synthetic route to the saturated congener 14 to determine the structure-activity relationship. ${ }^{51)}$ Manzamine C (12), despite its rather simple structure, shows some of the cytotoxic activity found in manzamine A. Therefore, the synthesis of $\mathbf{1 2}$ and related analogues is attractive from the perspective of the structure-activity relationship.

The formation of 11-membered rings by RCM is distinctly unusual. $\left.{ }^{4}\right)$ Gesson and co-workers successfully applied RCM to 11 -membered lactones from carbohydrate derivatives. ${ }^{52)}$ As shown in Chart 3, azacycloundecene compounds (16 or 17), which are key intermediates in our syntheses of 12 and 13, were prepared by cyclization of the ditosylates $\mathbf{1 5}$ derived from the corresponding alkyne. To investigate an alternate convenient method for the synthesis of $\mathbf{1 6}$ or $\mathbf{1 7}$, we studied the RCM of 18, which can be readily obtained in $83 \%$ yield by reacting $p$-toluenesulfonamide with 6-bromo-1-hexene. The results are shown in Table 2.

RCM with $10 \mathrm{~mol} \%$ of the Grubbs catalyst $\mathbf{D}$ in $\mathrm{CH}_{2} \mathrm{Cl}_{2}$ (20 mM) converted $\mathbf{1 8}$ to a single isomer of a cyclized product (16\% yield), which was identified as the $E$ isomer 17 by comparison with an authentic sample prepared previously, ${ }^{47,48)}$ together with dimeric products. On the other hand, the similar reaction of $\mathbf{1 8}$ in diluted solution $(20 \mathrm{~mm})$ gave two cyclized products, 17 (major) and the $Z$ isomer 16
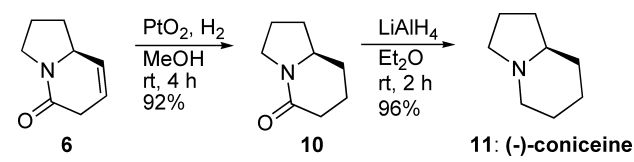

Chart 2. Synthesis of $(-)$-Coniceine (minor) (entry 2), which were readily separated by column chromatography. The yield was increased to $74 \%$ when the reactants were heated at $50{ }^{\circ} \mathrm{C}$ (entry 3 ).

We were interested in the biological activity of an oxygenfunctionalized analogue (19, Fig. 4), which was expected to be more soluble in water. Metathesis substrate $\mathbf{2 1}$ was prepared from diallylation of the corresponding diol, which was obtained in $66 \%$ yield from the reaction of protected bromoethanol with $p$-toluenesulfonamide (3 steps).

Reaction of 21 in $20 \mathrm{~mm}$ solution of $\mathrm{CH}_{2} \mathrm{Cl}_{2}$ or benzene using $10 \mathrm{~mol} \%$ of $\mathbf{D}$ gave dimeric compound $\mathbf{2 2}(62-67 \%)$ and $Z$-cycloundecene $20(11-25 \%)$ (Table 3, entries 1, 2).

Under more diluted conditions, in $2 \mathrm{~mm}$ solution, 20 became the main product (53\%, entry 3 ). The yield of $\mathbf{2 0} \mathrm{did}$

Table 2. RCM: Construction of Cycloundecen

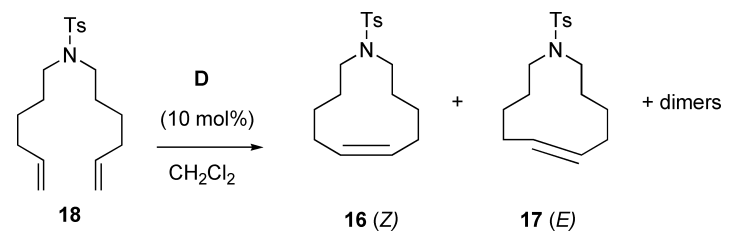

\begin{tabular}{cccccc}
\hline \hline Entry & $\begin{array}{c}\text { Substrate } \\
\text { conc. } \\
(\mathrm{mm})\end{array}$ & $\begin{array}{c}\text { Temp. } \\
\left({ }^{\circ} \mathrm{C}\right)\end{array}$ & $\begin{array}{c}\text { Reaction } \\
\text { time } \\
(\mathrm{h})\end{array}$ & $\begin{array}{c}\mathbf{1 6} \\
(\%)\end{array}$ & $\begin{array}{c}\mathbf{1 7} \\
(\mathbf{\%})\end{array}$ \\
\hline 1 & 20 & $\mathrm{rt}$ & 5.5 & 0 & 16 \\
2 & 2 & $\mathrm{rt}$ & 5.5 & 4 & 50 \\
3 & 2 & 50 & 2.5 & 12 & 62 \\
\hline
\end{tabular}
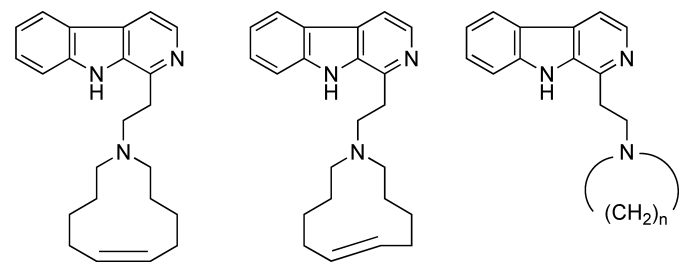

manzamine C (12) trans-manzamine C (13)

14

Fig. 3. Structure of Manzamine C

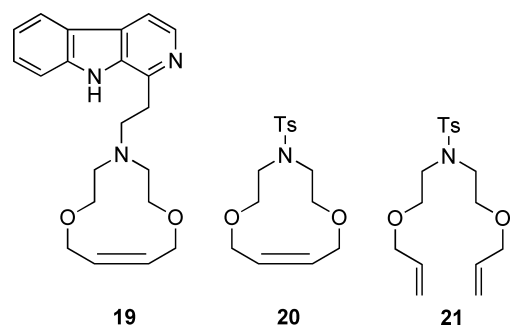

Fig. 4. Structure of Oxo-manzamine C

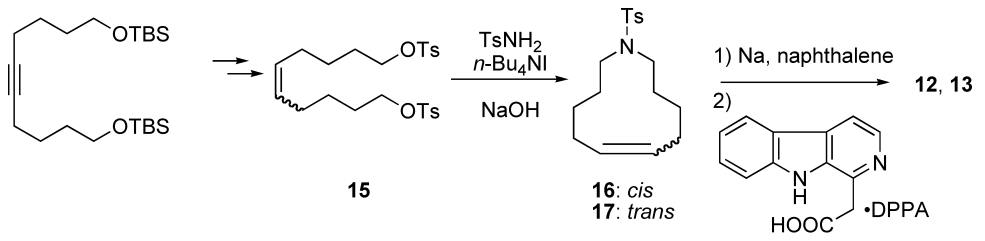

2) $\mathrm{LiAlH}_{4}$

Chart 3. Synthesis of Azacycloundecene 
not increase when the reaction mixture was heated. The structure of $\mathbf{2 0}$ was determined by X-ray analysis. In contrast to $\mathbf{1 8}$, the similar reaction of $\mathbf{2 1}$ gave only $Z$ isomer $\mathbf{2 0}$, probably for conformational reasons. Thus, it is clear that RCM is an effective method for preparing oxygen-containing $Z$-undecene intermediates for manzamine $\mathrm{C}$ analogues, compared to the conventional method, and will be extended to the synthesis of marine alkaloids.

1.1.3. Axially Chiral Macrolactams ${ }^{14,17)}$ : We recently reported that new axially chiral ligands, 1,1'-(2,2'-bisacylamino)binaphthalenes (BINAMIDE), are effective in the ytterbium-catalyzed asymmetric Diels-Alder reaction between cyclopentadiene and crotonyl-1,3-oxazolidin-2-one (Chart 4). ${ }^{53)}$

$1,1^{\prime}-\left(2,2^{\prime}\right.$-Bisacylamino)binaphthalenes $\quad(\mathbf{2 3}-\mathbf{2 5})$ were synthesized by reacting binaphthyldiamine with mixed anhydride of the corresponding acid, and then reacting the product with ruthenium carbene catalyst (D) under various condi-

Table 3. RCM: Construction of Oxygen Containing Cycloundecen

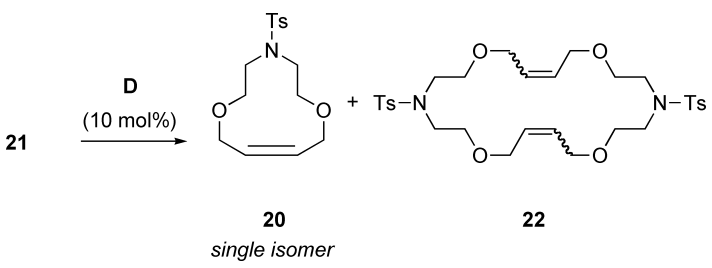

\begin{tabular}{clccccc}
\hline \hline Entry & Solvent & $\begin{array}{c}\text { Substrate } \\
\text { conc. } \\
(\mathrm{mm})\end{array}$ & $\begin{array}{c}\text { Temp. } \\
\left({ }^{\circ} \mathrm{C}\right)\end{array}$ & $\begin{array}{c}\text { Reaction } \\
\text { time }\end{array}$ & $\begin{array}{c}\mathbf{2 0} \\
(\%)\end{array}$ & $\begin{array}{c}\mathbf{2 2} \\
(\%)\end{array}$ \\
\hline 1 & $\mathrm{Benzene}^{\circ}$ & 20 & $\mathrm{rt}$ & $4 \mathrm{~d}$ & 11 & 62 \\
2 & $\mathrm{CH}_{2} \mathrm{Cl}_{2}$ & 20 & $\mathrm{rt}$ & $15 \mathrm{~h}$ & 25 & 67 \\
3 & $\mathrm{CH}_{2} \mathrm{Cl}_{2}$ & 2 & $\mathrm{rt}$ & $15 \mathrm{~h}$ & 53 & 32 \\
4 & $\mathrm{CH}_{2} \mathrm{Cl}_{2}$ & 2 & 50 & $15 \mathrm{~h}$ & 49 & 41 \\
\hline
\end{tabular}

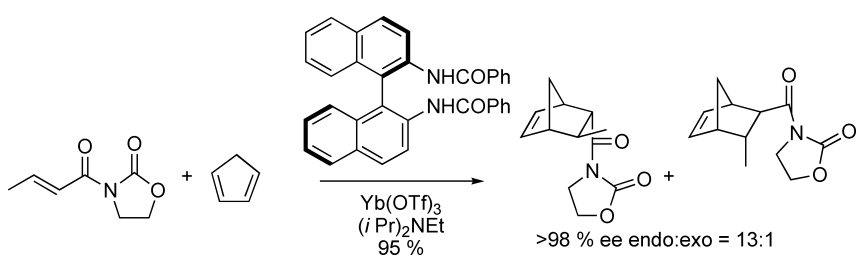

Chart 4. Diels-Alder Reaction Using Chiral BINAMIDE tions (Table 4).

Initial experiments were conducted on $\mathbf{2 3}$ in $\mathrm{CH}_{2} \mathrm{Cl}_{2}$ (34 mM) with Grubbs' catalyst $\mathbf{D}(10 \mathrm{~mol} \%)$ at room temperature. Although the yield was low, macrolactam 26 was obtained as a single isomer, which was assigned to be $E$ on the basis of its X-ray analysis. Dilution and less mild conditions $\left(50{ }^{\circ} \mathrm{C}\right)$ using $30 \mathrm{~mol} \%$ of $\mathbf{D}$ provided the best yield $(96 \%)$ of 26 (entry 2 ).

When RCM of 5-hexenoyl derivative $\mathbf{2 4}$ was carried out under similar reaction conditions, a remarkably different behavior was observed with regard to the reaction time and the products. The reaction proceeded more rapidly and a mixture of $E$ and $Z$ geometric isomers 27 was obtained in 63\% yield, favoring the $Z$ isomer in contrast to 23 , which could be separated by silica gel chromatography (entry 3 ). Dilution of the reaction mixture increased the yield of 27 to $89 \%$ (entry 4). RCM of 24 occurs most efficiently in $\mathrm{CH}_{2} \mathrm{Cl}_{2}$ at refluxing temperature using $5 \mathrm{~mol} \%$ of $\mathbf{D}$ (entry 5 ).

Starting with 6-heptenoyl amide 25, under similar conditions, the 18 -membered macrolactam $\mathbf{2 8}$ was also obtained as a mixture of $E$ and $Z$ isomers (entry 6). In this reaction, the $E$ isomer was mainly obtained.

It is generally recognised that one of the major problems in ring-closing ene-ene metathesis is how to control/predict the stereoselectivity in the formation of the new double bond. ${ }^{54-64)}$ In the RCM of dienes 23 and 25 to the 14-membered lactam 26 and the 18-membered lactam 28, $E$-isomers are the major products. On the other hand, the RCM of $\mathbf{2 4}$ to the 16-membered ring lactam 27 gave a $Z$-isomer as the major product (Table 4).

As shown in Chart 5, a stereocontrolled RCM product (30) might be useful as a key intermediate for chiral ligands, while the symmetric dicarboxylic acid (31) is a typical metabolite of patients who lack medium acyl CoA dehydrogenase. ${ }^{65)}$ To the best of our knowledge, the preparation of 31, which might be used as a building block for biologically active natural products, has not yet been reported. Although it is not yet clear what factors control the stereoselectivity, we studied the RCM reactions of tethered $d i$-hexenoyl derivatives under various conditions (i.e., with various solvents, catalysts, and templates) and examined the stereoselectivity of the reaction leading to the new double bond. Among these conditions, the selection of a template was found to be the most effective way to influence stereoselectivity and that the

Table 4. RCM of Bisacylamino Binaphthalenes

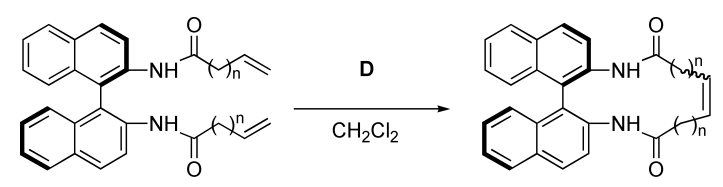

23: $n=2,24: n=3,25: n=4$

26: $n=2,27: n=3,28: n=4$

\begin{tabular}{|c|c|c|c|c|c|c|c|c|}
\hline Entry & Substrate & $\begin{array}{c}\text { D } \\
(\mathrm{mol} \%)\end{array}$ & $\begin{array}{l}\text { Conc. } \\
(\mathrm{mm})\end{array}$ & $\begin{array}{c}\text { Temp. } \\
\left({ }^{\circ} \mathrm{C}\right)\end{array}$ & $\begin{array}{l}\text { Time } \\
\text { (h) }\end{array}$ & Product & $\begin{array}{c}\text { Yield } \\
(\%)\end{array}$ & \\
\hline 1 & 23 & 10 & 34 & $\mathrm{rt}$ & 18 & 26 & 14 & $E$ only \\
\hline 2 & 23 & 30 & 11 & 50 & 15 & 26 & 96 & $E$ only \\
\hline 3 & 24 & 30 & 11 & 50 & 2.5 & 27 & 63 & $E / Z=1 / 2.0$ \\
\hline 4 & 24 & 30 & 1 & 50 & 2 & 27 & 89 & $E / Z=1 / 2.1$ \\
\hline 5 & 24 & 5 & 6 & 50 & 2.5 & 27 & 94 & $E / Z=1 / 2.5$ \\
\hline 6 & 25 & 5 & 7 & 50 & 6 & 28 & 90 & $E / Z=4.7 / 1$ \\
\hline
\end{tabular}



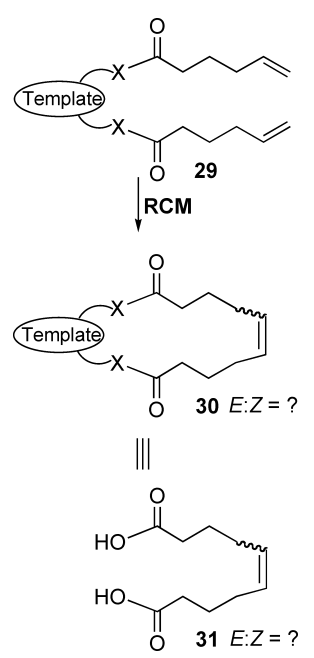

Chart 5. Synthesis of $D i$-hexenoyl Derivatives
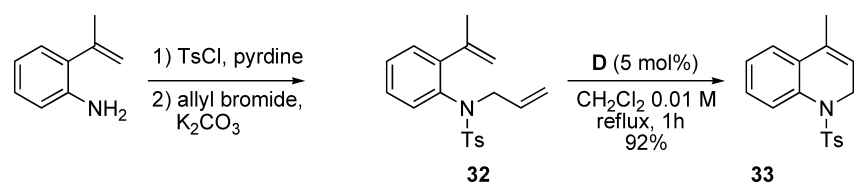

Chart 6. Synthesis of 1,2-Dihydroquinoline Using RCM

desired isomer could be obtained as a major product.

These structures of cyclized macrolactams are quite novel and have a unique axial angle compared to the corresponding precursors, which would be expected to make them useful for asymmetric reactions.

1.1.4. 1,2-Dihydroquinolines: Quinoline is a major class of alkaloid and plays an important role in the fields of natural products and medicinal chemistry. Several methods for synthesizing quinoline have been known since the late 1800s. However, despite their versatility, these conventional methods have several drawbacks. First, these reactions usually require high temperature and/or strongly acidic conditions, which leads to the decomposition of products and a tedious isolation procedure. Regioselectivity is another problem with the intramolecular electrophilic substitution of unsymmetrically substituted aniline derivatives. To overcome these problems, modern synthetic methods for quinoline using a transition metal-catalyst, such as ruthenium, palladium, rhodium, iron, copper, manganese or cobalt, have been investigated. ${ }^{66-86)}$

In our continuing study of the RCM reaction and our approaches to the synthesis of novel antimalarial agents, ${ }^{87)}$ we developed a novel method for synthesizing substituted 1,2dihydroquinolines using ene-ene metathesis and silyl or alkyl enol ether-ene metathesis, which proceeds under mild conditions and gives an excellent yield. This process leads to spontaneous air oxidation to quinoline after deprotection. We also describe its application to the synthesis of key intermediates for antimalarial agents, such as quinine, chloroquine, and PPMP-quinine hybrid and total synthesis of augustureine.

We first investigated RCM conditions for $\alpha, \omega$-diene $\mathbf{3 2}$ derived from commercially available 2-isopropenylaniline (Chart 6). When $\mathbf{3 2}$ was reacted with $5 \%$ of catalyst $\mathbf{D}$ in $\mathrm{CH}_{2} \mathrm{Cl}_{2}$ at refluxing temperature for $1 \mathrm{~h}$, the corresponding
Table 5. Synthesis of 1,2-Dihydroquinoline Using RCM

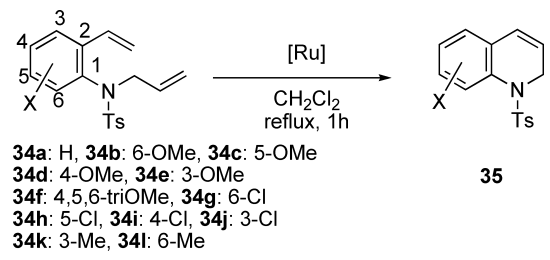

\begin{tabular}{cccc}
\hline \hline Entry & Substrate & {$[\mathrm{Ru}]$} & Yield (\%) \\
\hline 1 & $\mathbf{3 4 a}$ & $\mathbf{D}$ & 93 \\
2 & $\mathbf{3 4 b}$ & $\mathbf{D}$ & 100 \\
3 & $\mathbf{3 4 c}$ & $\mathbf{D}$ & 90 \\
4 & $\mathbf{3 4 d}$ & $\mathbf{E}$ & 95 \\
5 & $\mathbf{3 4 e}$ & $\mathbf{D}$ & 74 \\
6 & $\mathbf{3 4 \mathbf { f }}$ & $\mathbf{E}$ & 90 \\
7 & $\mathbf{3 4 g}$ & $\mathbf{D}$ & 87 \\
8 & $\mathbf{3 4 h}$ & $\mathbf{D}$ & 100 \\
9 & $\mathbf{3 4 i}$ & $\mathbf{E}$ & 90 \\
10 & $\mathbf{3 4 j}$ & $\mathbf{D}$ & 100 \\
11 & $\mathbf{3 4 k}$ & $\mathbf{D}$ & 95 \\
12 & $\mathbf{3 4 l}$ & $\mathbf{D}$ & 100 \\
\hline
\end{tabular}

Table 6. Effect of Protective Groups on Nitrogen

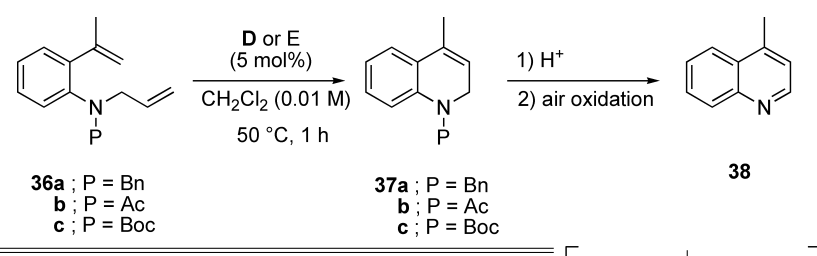

\begin{tabular}{crcc}
\hline \hline Entry & Substrate & Ru-catalyst & Product $\mathbf{3 8}(\%)$ \\
\hline 1 & $\mathbf{3 6 a}$ & $\mathbf{D}$ & 95 \\
2 & $\mathbf{b}$ & $\mathbf{D}$ & 0 \\
3 & $\mathbf{b}$ & $\mathbf{E}$ & 98 \\
4 & $\mathbf{c}$ & $\mathbf{D}$ & 63 \\
5 & $\mathbf{c}$ & $\mathbf{E}$ & 97 \\
\hline
\end{tabular}

1,2-dihydroquinoline 33 was obtained in $92 \%$ yield.

We examined the scope and limitations of RCM for 1,2-dihydroquinoline synthesis. Various dienes were prepared from anthranilic acid derivatives and subjected to RCM reaction. The results are summarized in Table 5 .

The reaction of $34 \mathbf{a}-\mathbf{l}$ with $\mathbf{E}(5 \mathrm{~mol} \%)$ in refluxing $\mathrm{CH}_{2} \mathrm{Cl}_{2}$ for $1 \mathrm{~h}$ gave the corresponding 1,2-dihydroquinolines (35a-l) via RCM in good to excellent yields (Table 5) regardless of the substituents (methoxy, chloro or methyl) on the aromatic ring. Having established the RCM conditions, we next examined the effect of protecting groups on nitrogen. Dienes $36 \mathbf{a}-\mathbf{c}$, which were readily prepared from commercially available $o$-aminostyrene, were reacted with both catalysts $\mathbf{D}$ and $\mathbf{E}$. The reaction of $N$-benzyl derivative 36a with catalyst $\mathbf{D}$ gave $37 \mathbf{a}$ in excellent yield (Table 6 , entry 1 ), while $N$-acetyl derivative $36 \mathbf{b}$ did not give the desired cyclized product (entry 2). In this case, catalyst $\mathbf{E}$ probably reacted with the terminal double bond in $\mathbf{3 6} \mathbf{b}$ to form the chelated intermediate 39, which prohibited further RCM. When $N$-tert-butoxycarbonyl derivative $\mathbf{3 6 c}$ was treated with catalyst $\mathbf{D}$ under similar conditions, 1,2-dihydroquinoline 37c was obtained in modest yield. On the other hand, with catalyst $\mathbf{E}$, the yields of $\mathbf{3 6} \mathbf{b}$ and $\mathbf{3 6 c}$ dramatically increased 
Table 7. Effect of Ru-Catalysts on the RCM of Dienes $\mathbf{4 0}$ and $\mathbf{4 1}$

\begin{tabular}{|c|c|c|c|c|}
\hline Entry & Substrate & Ru-catalyst & Product & Yield (\%) \\
\hline 1 & & D & & 100 \\
\hline 2 & & $\mathbf{E}$ & & 100 \\
\hline 3 & & D & & 95 \\
\hline 4 & & $\mathbf{E}$ & & 99 \\
\hline
\end{tabular}

to give $37 \mathbf{b}$ and $37 \mathbf{c}$, respectively, in almost quantitative yields (entries 3,5 ). The protective groups on nitrogen of products $37 \mathbf{a}-\mathbf{c}$ were readily removed during silica gel column chromatography to give 1,2-dihydroquinolines, which were spontaneously oxidized to give 4-methylquinoline $\mathbf{3 8}$ quantitatively.

We next investigated a similar RCM for medium-sized rings such as in benzoazepine and benzoazocine. Dienes 40 and 41 were subjected to the above reaction conditions using both Grubbs' catalysts (D, E). The reaction of $\mathbf{4 0}$ and $\mathbf{4 1}$ in the presence of catalyst $\mathbf{D}$ gave only the dimeric products $\mathbf{4 2}$ and 44, respectively. In sharp contrast, the corresponding benzoazepine 43 and benzoazocine 45 were obtained with catalyst $\mathbf{E}$ in excellent yields (Table 7). Isolated $\mathbf{4 2}$ and $\mathbf{4 4}$ were converted to $43(5 \mathrm{~h}, 98 \%)$ and 45 (6 h, 97\%), respectively, under the same conditions using catalyst $\mathbf{E}$.

1.1.4.1. Silyl enol ether-ene metathesis ${ }^{16)}$ : Many quinoline alkaloids which show important bioactivities, such as quinine and chloroquine, contain substituents at the 4-position. Therefore, we next focused our attention on extending this reaction to the synthesis of 4-substituted quinolines. For this purpose, we studied the synthesis of 4-methoxy- and 4siloxy-1,2-dihydroquinolines, which, in turn, could be converted to various 4-substituted quinolines, using ene-enol ether metathesis (Table 8).

Enol methyl ether 46a and enol silyl ether 46b were prepared from commercially available $o$-aminoacetophenone and subjected to our reaction conditions using catalysts $\mathbf{D}$ and $\mathbf{E}$, respectively. When enol methyl ether 46a and enol silyl ether $\mathbf{4 6 b}$ were treated with $\mathbf{D}$, the cyclized product was not obtained at all and the starting materials were recovered (entries 1, 3). In contrast, treatment of the same substrates with catalyst $\mathbf{E}$ gave the corresponding 4-methoxy-1,2-dihydroquinoline $47 \mathbf{a}$ and 4-siloxy-1,2-dihydroquinoline $\mathbf{4 7 b}$ in $95 \%$ yield, respectively (entries 2,4 ). This novel synthetic method could be applied to large-scale, multigram, syntheses.

1.1.4.2. Formal synthesis of chloroquine, chinine, PPMP-quinine hybrid ${ }^{21)}$ : Encouraged by these results, we applied this novel method to the synthesis of key intermediates of antimalarial agents, such as quinine, ${ }^{88-92)}$ chloro-
Table 8. Effect of Ru-Catalyst on the Ene-Enol Metathesis of 46a and 46b

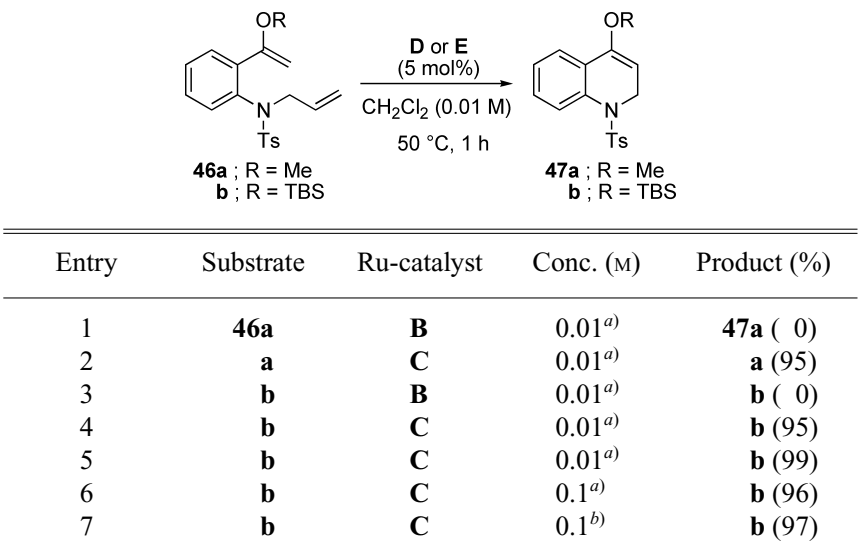

a) Degassed conditions. b) Without degassing.

quine, ${ }^{93,94)}$ and PPMP-quinine hybrid, ${ }^{87)}$ which are shown in Chart 7.

1.1.4.3. Total synthesis of angustureine and determination of its absolute structure ${ }^{24)}$ : A novel 2-substituted quinoline alkaloid, angusturiene, was isolated from Galipea officinalis HANCOCK by Jacquemond-Collet et al. in 1999. ${ }^{95)}$ The same plant has been previously investigated and 5 quinoline alkaloids have already been reported by Rakotoson et al. in $1998 .^{96)}$ Genus Galipea AUBLET is composed of approximately 20 species including Galipea officinalis HANCOCK, a shrub indigenous to the mountains of Venezuela that is known to contain 2-substituted quinoline alkaloids. These alkaloids were formerly used in folk medicine as bitter tonic to treat dyspepsia, dysentery and chronic diarrhea, and fever. ${ }^{97)}$ The ethanolic extract from the bark of $G$. officinalis, called angostura, possesses activity against Mycobacterium tuberculosis. ${ }^{98)}$ Recently, the antimalarial and cytotoxic activities of angusturiene, galipeine, cuspareine and galipinine have also been reported (Fig. 5). ${ }^{99)}$

Although the natural angusturiene is one of the main isolated fraction ( $980 \mathrm{mg}$ from $1 \mathrm{~kg}$ of dried bark), its absolute configuration had not yet been reported by the time we 
<smiles>CCCCCC1CCc2ccccc2N1C</smiles>

angustureine<smiles>COc1ccc(CCC2CCc3ccccc3N2C)cc1OC</smiles>

cuspareine
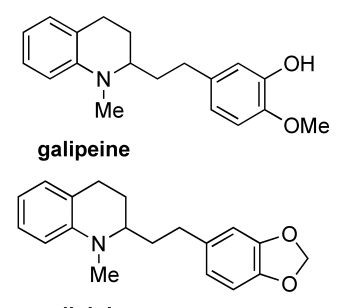

galipinine
Fig. 5. Structures of 2-Substituted Quinoline Alkaloids with Anti-malarial Activity Isolated from Galipea offinalis started this research project. ${ }^{95)}$ In the middle of our synthetic study, Wang et al. described the synthesis of angusturiene using iridium-catalyzed hydrogenation. ${ }^{100}$ ) We would like to present our independent and original synthesis of optically pure $(+)-(S)$-angusturiene and determination of the absolute configuration of the natural product, angusturiene.

As shown in Chart 8, the synthesis of angusturiene began with Wittig olefination to convert readily available 2-nitrobenzaldehyde 48 to styrene 49 , followed by treatment of 49 with $\mathrm{Zn}$ powder in $\mathrm{AcOH}$ to afford aniline 50. Tosylation of the resulting amino group proceeded to give tosylated ani-<smiles>C=CCN(C)c1ccc(OC)cc1C(=C)C</smiles>

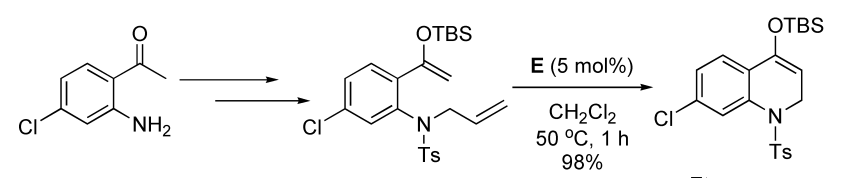<smiles>CCOCCCC(C)Nc1ccnc2cc(Cl)ccc12</smiles>

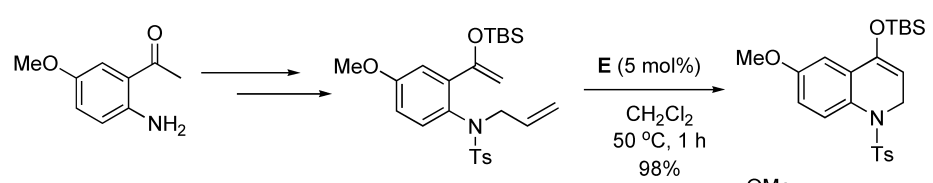<smiles>COc1ccc2ncc(CC(C)C)c(O)c2c1</smiles>

Chart 7. RCM Based Preparation of Key Intermediate for Quinine, Chloroquine and Quinine-PPMP Hybrid

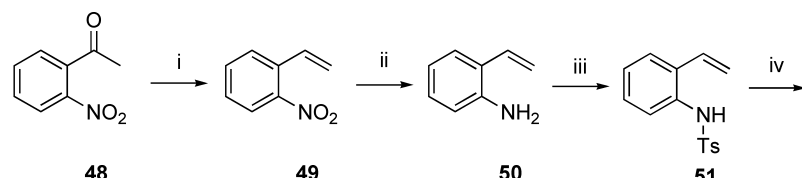

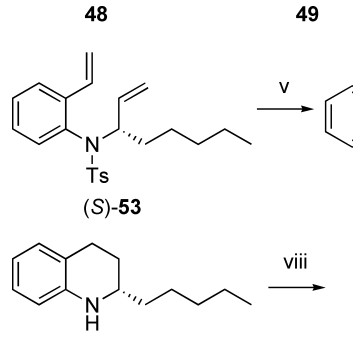

(S)-56
50 51

(i) $\mathrm{Ph}_{3} \mathrm{PMeBr}, \mathrm{KN}(\mathrm{TMS})_{3}, \mathrm{THF}, 20^{\circ} \mathrm{C}, 1 \mathrm{~h}, 90 \%$; (ii) $\mathrm{Zn}$ powder, $\mathrm{AcOH}, 20^{\circ} \mathrm{C}, 2 \mathrm{~h}, 68 \%$; (iii) $\mathrm{TsCl}$, pyridine, $\mathrm{CH}_{2} \mathrm{Cl}_{2}, 20^{\circ} \mathrm{C}, 1 \mathrm{~h}, 86 \%$; (iv) $(R)-\mathrm{CH}_{2}=\mathrm{CH}-\mathrm{CH}(\mathrm{OH})-\left(\mathrm{CH}_{2}\right)_{4}-\mathrm{CH}_{3}$ 52, DEAD, $\mathrm{PPh}_{3}$, THF, $20^{\circ} \mathrm{C}, 2 \mathrm{~h}, 78 \%$; (v) Ru catalyst $\mathrm{E}, \mathrm{CH}_{2} \mathrm{Cl}_{2} 0.01 \mathrm{M}, 50^{\circ} \mathrm{C}, 1 \mathrm{~h}, 92 \%$; (vi) $\mathrm{Pt}_{2} \mathrm{O}, \mathrm{H}_{2}, \mathrm{MeOH}, 20^{\circ} \mathrm{C}$, $12 \mathrm{~h}, 94 \%$; (vii) naphthalene sodium, DME, $-65^{\circ} \mathrm{C}, 10 \mathrm{~min}, 99 \%$; (viii) $\mathrm{Mel}, \mathrm{K}_{2} \mathrm{CO}_{3}, \mathrm{THF}, 85^{\circ} \mathrm{C}, 80 \%$.

Chart 8. Synthesis of Angusturiene 
line $\mathbf{5 1}$ in $86 \%$ yield.

Installation of a C-2 side chain was accomplished by employing Mitsunobu reaction as the first key step with readily available $(R)$-alcohol 52 in the presence of DEAD and $\mathrm{PPh}_{3}$ to give the desired $\alpha, \omega$-diene $\mathbf{5 3}$ in $78 \%$ yield, $99 \%$ ee. $^{101)}$ With substrate $\mathbf{5 3}$ in hand, RCM as the second key step was undertaken to furnish a quinoline skeleton using catalyst $\mathbf{E}$ $0.01 \mathrm{M}$ in $\mathrm{CH}_{2} \mathrm{Cl}_{2}$ at $50^{\circ} \mathrm{C}$ for $1 \mathrm{~h}$. The corresponding 1,2-dihydroquinoline was obtained in $92 \%$ yield. Next, hydrogenation of dihydroquinoline $\mathbf{5 4}$ with Adam's catalyst in $\mathrm{MeOH}$ under $\mathrm{H}_{2}$ atmosphere gave tetrahydroquinoline 55 in $94 \%$ yield, followed by detosylation resulting in tetrahydroquinoline 56 quantitatively. Finally, methylation of free nitrogen enabled the completion of $(+)-(S)$-angusturiene synthesis in $80 \%$ yield. HPLC analysis indicated synthesized $(+)-(S)$-angusturiene had $94 \%$ ee, $[\alpha]_{\mathrm{D}}^{23}+7.91^{\circ}\left(c=1.00 \mathrm{CHCl}_{3}\right),[\alpha]_{\mathrm{D}}^{26}$ $+4.35^{\circ}\left(c=1.00 \mathrm{CH}_{2} \mathrm{Cl}_{2}\right) ;[\alpha]_{\mathrm{D}}^{26}+5.18^{\circ}(c=1.00 \mathrm{MeOH})$; $[\alpha]_{\mathrm{D}}^{26}+5.10^{\circ}(c=1.00 \mathrm{EtOH})$, lit. $^{95)}[\alpha]_{\mathrm{D}}-7.16^{\circ}$.

1.1.4.4. 2-Quinolinone ${ }^{26)}:$ 2-Quinolinones are valuable intermediates in organic synthesis ${ }^{102)}$ and $N$-sulfonyl-2quinolinones are difficult to prepare by conventional methods because $O$-sulfonyl-2-quinolinones would be obtained preferentially instead of $N$-sulfonylation. In our previous work on the synthesis of dynemicin $\mathrm{A},{ }^{103)}$ we found that $N$-protected2-quinolinone derivatives are good dienophiles for the Diels-Alder reaction (Chart 9). Theoretically, $\mathrm{N}$-sulfonyl-2quinolinones are better dienophiles than $N$-methoxycarbonyl or $N$-methoxymethyl derivatives. However, we could not prepare $N$-sulfonyl-2-quinolinones using conventional methods.

Dienes (57) were prepared by condensation of the corresponding $N$-protected aniline and acid chloride. When catalyst $\mathbf{E}$ was used for RCM of 57a under the standard conditions, no cyclized product was obtained and the starting ma-

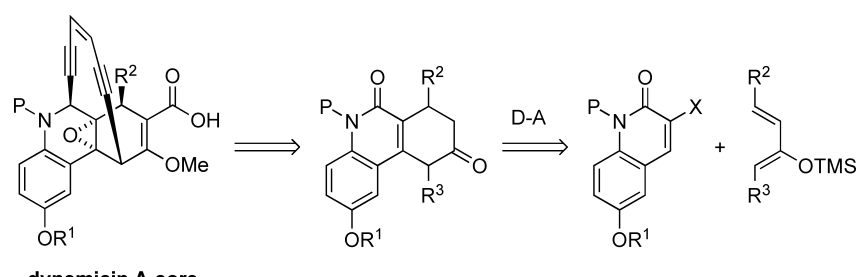

dynemicin A core

Chart 9. Diels-Alder Reaction for Dynemicin A Core

Table 9. Preparation of $\mathrm{N}$-Sulfonyl-2-quinolinone
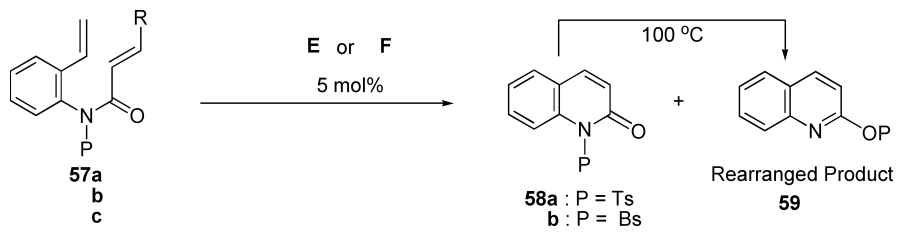

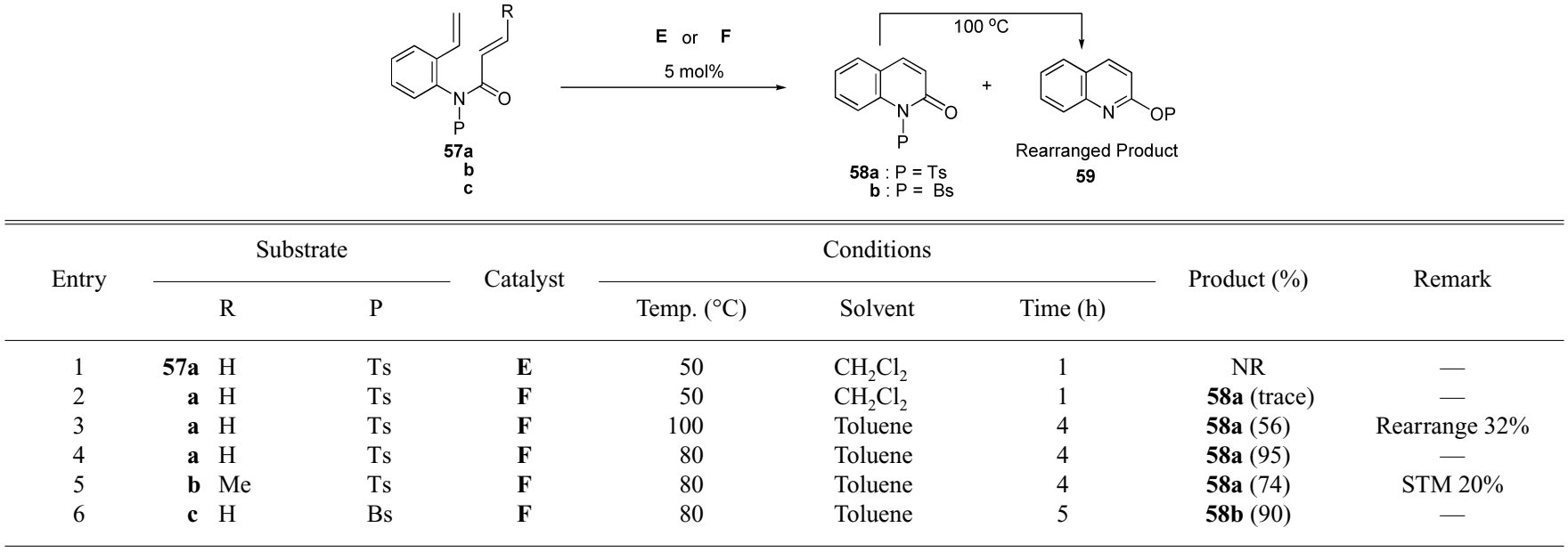

terial was recovered (Table 9, entry 1). Thus, instead of catalyst $\mathbf{E}$, catalyst $\mathbf{F}$ was used under the same reaction conditions. The $N$-tosyl-2-quinolinone 58a was obtained in trace amounts. When the reaction temperature was raised to $100{ }^{\circ} \mathrm{C}, N$-tosyl-2-quinolinone $\mathbf{5 8 a}$ was obtained in $56 \%$ yield, while rearranged product $\mathbf{5 9}$ was also obtained in $32 \%$ yield (entry 3 ). In entry 4 , the reaction temperature was reduced to $80^{\circ} \mathrm{C}$, the reaction mixture was stirred for $4 \mathrm{~h}$, and the desired $N$-tosyl-2-quinolinone 58a was obtained in quantitative yield. Thermal rearrangement of $\mathbf{5 8}$ to $\mathbf{5 9}$ occurred at $100{ }^{\circ} \mathrm{C}$ quantitatively without any catalyst. Compound 59 should be a useful substrate for the synthesis of 2-substituted quinolines by a coupling reaction.

$\mathrm{N}$-Crotonoyl- $N$-tosylaminostyrene $\mathbf{5 7 b}$ was subjected to the same reaction conditions as in entry 4 and gave $N$-tosyl2-quinolinone 58a in 74\% yield (entry 5). RCM of 57c was accomplished within $5 \mathrm{~h}$ using catalyst $\mathbf{F}$, and $N$-benzenesulfonyl-2-quinolinone $\mathbf{5 8 b}$ was obtained in 90\% yield (entry $6)$.

Thus, the development of a novel method for preparing $N$ sulfonyl-2-quinolinone was achieved by RCM using a welldefined Hoveyda catalyst $(\mathbf{E})$ and dienes at $80^{\circ} \mathrm{C}$. The reaction proceeded efficiently under mild conditions.

\subsection{Ruthenium Hydride, A}

1.2.1. Selective Isomerization of Terminal Olefin and Synthesis of Substituted Indole ${ }^{18)}$ : According to our findings regarding silyl enol ether-ene metathesis, we attempted the cross-metathesis of silyl enol ether with terminal olefin. Although this cross-metathesis did not succeed, we found that selective isomerization of terminal olefin $\left(\mathrm{R}-\mathrm{CH}_{2}-\mathrm{CH}=\mathrm{CH}_{2}\right)$ to internal alkene $\left(\mathrm{R}-\mathrm{CH}=\mathrm{CH}-\mathrm{CH}_{3}\right)$ took place, when $5 \mathrm{~mol} \%$ of catalyst $\mathbf{E}$ was used together with 10 eq of vinyloxytrimethylsilane (61a) (Table 10). This novel isomerization is effective for monosubstituted terminal olefins (Table 11).

Indole synthesis has been the subject of intensive investigations, especially in the areas of alkaloid synthesis and medicinal chemistry. ${ }^{104)}$

Our conditions favor isomerization rather than metathesis as a competitive reaction. This notable characteristic reaction is clearly demonstrated using $\mathrm{N}$-allyl-o-vinylaniline (34). Through optimization of the amount of 61a for 34a, it became clear that 1 eq of 61a was sufficient to convert 34a to the enamide (65a) in excellent yield (Table 12). Subsequent 
treatment of $\mathbf{6 5} \mathbf{a}$ without purification (obtained by evaporation of the solvent) with $\mathbf{E}$ ( $5 \mathrm{~mol} \%$ ) in refluxing benzene for $1 \mathrm{~h}$ gave indole (66a) in quantitative yield. These results provide the first example of aromatic enamide metathesis and indole synthesis using RCM. The effect of the substituent on nitrogen was examined, and the results are shown in Table 13. Not only $p$-toluenesulfonyl, but also acetyl, benzoyl, tertbutoxycarbonyl, benzyloxycarbonyl and methanesulfonyl derivatives gave the corresponding indoles (66) via enamides (65).

To clarify the scope and limitations of this indole synthesis, the effect of the substituent on the aromatic ring was examined, and the results are summarized in Table 14. Under our optimized reaction conditions, 34a-l gave enamide $(65 a-1)$ quantitatively. Although substituents at the ortho position of styrene in $\mathbf{3 4}$, such as in $\mathbf{3 4} \mathbf{e}, \mathbf{3 4} \mathbf{j}$, and $\mathbf{3 4} \mathbf{k}$, prevented cyclization to give the corresponding indoles (entries $5,10,11)$ probably due to steric and/or chelating effects, other substrates gave the corresponding RCM product in good to excellent yields.

1.2.2. Synthesis of Indoline Using Cycloisomerization: After our discovery of olefin isomerization using $\mathbf{E}$, we envisioned that the cycloisomerization of $\mathbf{3 4}$ might proceed at higher temperature. As shown in Table 15, the reaction of 34a and 61a with $\mathbf{E}$ gave 65a exclusively (entry 1). In contrast to the reaction in $\mathrm{CH}_{2} \mathrm{Cl}_{2}$, the same reaction in refluxing xylene gave 67a as the major product (entry 4) together with 65a. When $10 \mathrm{~mol} \%$ of $\mathbf{E}$ was used, the yield of $\mathbf{6 7 a}$ in-

Table 10. Reaction of $\mathbf{6 0}$ with Various Sily Enol Ethers and Vinyl Ethers in the Presence of Ruthenium Carbene Catalyst (E)

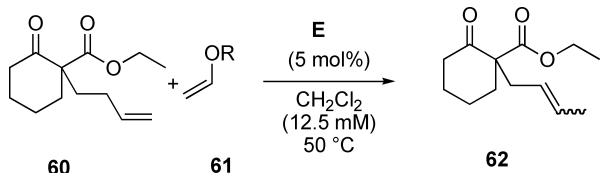

60

Enol ethers

\begin{tabular}{cccrccc}
\hline \multirow{2}{*}{ Entry } & \multicolumn{2}{c}{ Enol ethers } & & \\
\cline { 2 - 5 } & \multicolumn{2}{c}{$\mathrm{R}$} & eq & & & \\
& & & & & & \\
1 & 61a & TMS & 2 & 20 & 60 & $2.6 / 1$ \\
2 & 61a & TMS & 10 & 3 & Quant. & $3.5 / 1$ \\
3 & 61b & Ac & 10 & 23 & NR & \\
4 & 61c & Et & 10 & 3 & 12 & $\left.-^{b}\right)$ \\
5 & 61c & Et & 10 & 24 & Quant. & $3.2 / 1$ \\
\hline
\end{tabular}

a) The ratio were determined by ${ }^{1} \mathrm{H}-\mathrm{NMR}$. b) Not determined. creased to $81 \%$.

The effect of the substituent at the nitrogen was examined, and the results are summarized in Table 16. Acetyl, benzoyl, tert-butoxycarbonyl, benzyloxycarbonyl, and methanesulfonyl derivatives gave cycloisomerized products $(67,68)$ in yields of 69 to $99 \%$. Sulfonamide and derivatives $(\mathbf{3 4 a}, \mathbf{q})$ gave indoline (67) in excellent yields. The reaction of methanesulfonyl derivative (34q) with $1 \mathrm{~mol}$ eq of $\mathbf{6 1 a}$ gave a mixture of $67(71 \%)$ and 1,2-dihydroquinoline (29\%), indicating that 1 eq of 61a was not sufficient for the formation of 67. Consequently, the yield of 67 increased up to $86 \%$ with the use of 3 eq of 61a (entry 6).

To determine the scope and limitations of the present catalytic reactions, the substituent effect was examined using several substrates $(\mathbf{3 4 a}-\mathbf{l})$, and selected results are shown in Table 17. All of the substrates, except 34b, 34f and 34g, gave cycloisomerized products in yields of 24 to $84 \%$. This methodology was also extended to the construction of 3methylene-2,3-dihydrobenzofuran $(\mathbf{7 0 a}-\mathbf{c})$. As shown in Table 18, when $O$-allyl-o-vinylphenol derivatives $(\mathbf{7 0 a}-\mathbf{c})$ were refluxed in toluene with $\mathbf{E}$ and $\mathbf{6 1 a}, \mathbf{7 0 a}-\mathbf{c}$ were obtained in reasonable yields, except that 69d gave only isomerization product in low yield and 69d was recovered in $62 \%$ yield. The results with $\mathbf{3 4 b}, \mathbf{3 4 f}, \mathbf{3 4 g}$ and $\mathbf{6 9 d}$ suggest that chelation between the $O$-substituent with $\mathrm{Ru}$ catalyst and/or steric effects might prevent cycloisomerization.

As a further application, the cycloisomerization of a variety of $N$-functionalized alkyl-o-vinylanilines was examined. The reactions of $\mathbf{3 4 r}, \mathbf{s}$, and $\mathbf{t}$ were performed with $1 \mathrm{eq}$ of 61a with $\mathbf{E}$ in refluxing xylene for $2 \mathrm{~h}$ (Table 19). Diene 34r gave cycloisomerization product $67 \mathrm{r}$ as the major product to-

Table 12. Optimization of the Amount of 61a for 34a

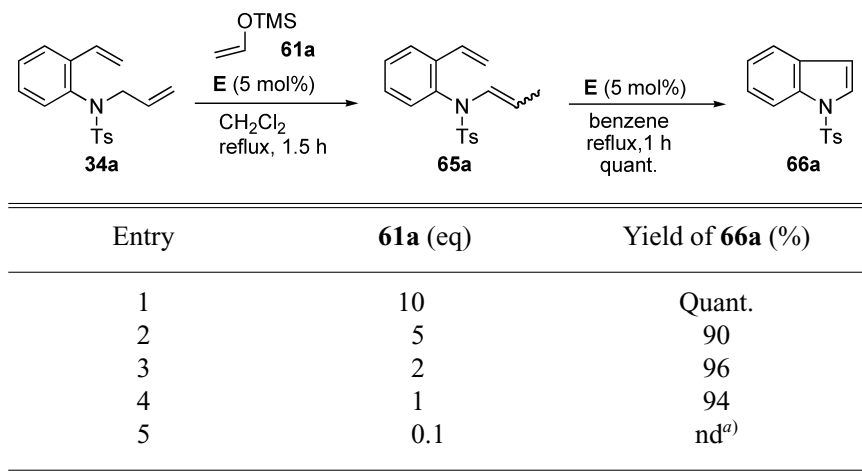

a) Mixture of enamide, 1,2-dihydroquinoline and indole $(0.41 / 0.17 / 1)$.

Table 11. Novel Isomerization of Various Terminal Olefins

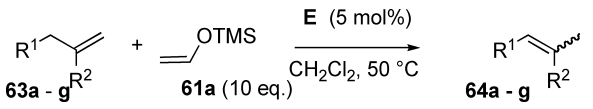

\begin{tabular}{|c|c|c|c|c|c|c|}
\hline Entry & Substrate & $\mathrm{R}^{1}$ & $\mathrm{R}^{2}$ & Time (h) & Yield $(\%)^{a)}$ & $E / Z^{b)}$ \\
\hline 1 & $63 a$ & $\mathrm{Ph}$ & $\mathrm{H}$ & 1.5 & Quant. (34) & $12.8 / 1$ \\
\hline 2 & $63 b$ & $\mathrm{PhCH}_{2}$ & $\mathrm{H}$ & 3.0 & 58 & $2.8 / 1$ \\
\hline 3 & $63 c$ & $p-\mathrm{MeOC}_{6} \mathrm{H}_{4} \mathrm{CH}_{2}$ & $\mathrm{H}$ & 3.0 & 78 & $8.5 / 1$ \\
\hline 4 & 63d & $\mathrm{HO}\left(\mathrm{CH}_{2}\right)_{3}$ & $\mathrm{H}$ & 3.0 & Quant. (34) & $6.1 / 1$ \\
\hline 5 & $63 e$ & $\mathrm{BnO}\left(\mathrm{CH}_{2}\right)_{3}$ & $\mathrm{H}$ & 3.0 & Quant. (96) & $8.2 / 1$ \\
\hline 6 & $63 f$ & $\mathrm{BnO}$ & $\mathrm{H}$ & 3.0 & 73 & $1 / 1.25$ \\
\hline 7 & $63 \mathrm{~g}$ & $\mathrm{BnOCH}_{2}$ & $\mathrm{CH}_{3}$ & 3.0 & NR & - \\
\hline
\end{tabular}

a) Yields in parenthesis indicate the isolated yields. b) Determined by ${ }^{1} \mathrm{H}-\mathrm{NMR}$. 
Table 13. Indole Synthesis: Substituent Effect on Nitrogen

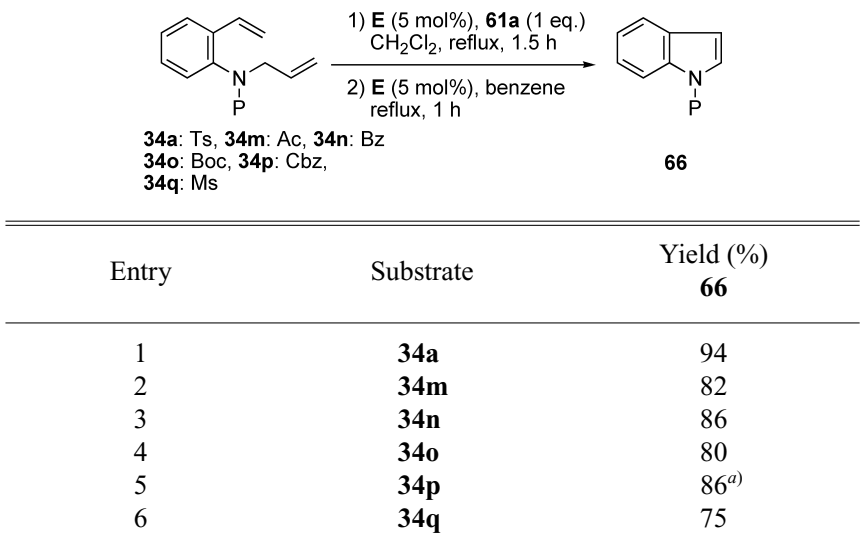

a) Reaction time of RCM was $16 \mathrm{~h}$

Table 14. Synthesis of Indole (66) from 34

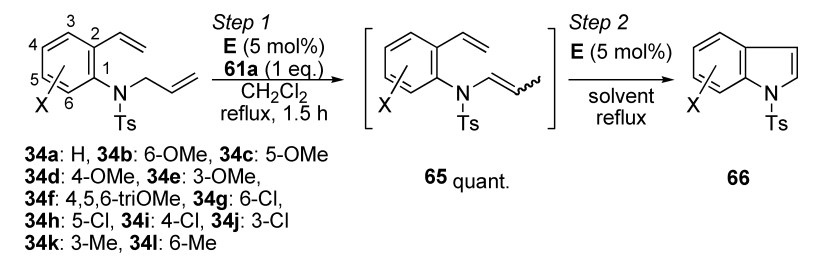

\begin{tabular}{|c|c|c|c|c|c|}
\hline \multirow{2}{*}{ Entry } & \multirow{2}{*}{ Substrate } & \multicolumn{2}{|c|}{ Reaction conditions of Step 2} & \multicolumn{2}{|c|}{ Product (\%) } \\
\hline & & Solvent & Reaction time & 66 & 65 \\
\hline 1 & $34 a$ & Benzene & 1 & 94 & - \\
\hline 2 & $34 b$ & Benzene & 1 & 83 & - \\
\hline 3 & $34 c$ & Toluene $e^{b, c)}$ & 16 & 96 & - \\
\hline 4 & 34d & Benzene & 3 & 100 & - \\
\hline 5 & $34 \mathrm{e}$ & Toluene $\mathrm{e}^{b, d)}$ & 32 & 54 & 46 \\
\hline 6 & $34 \mathrm{f}$ & Toluene $^{b)}$ & 17 & 83 & - \\
\hline 7 & $34 \mathrm{~g}$ & Toluene $^{b)}$ & 4.5 & 85 & - \\
\hline 8 & $34 \mathrm{~h}$ & Toluene $^{b)}$ & 13 & 79 & - \\
\hline 9 & $34 i$ & Toluene $^{b)}$ & 2 & 86 & - \\
\hline 10 & $\mathbf{3 4} \mathbf{j}^{a)}$ & Toluene $^{b)}$ & 24 & 33 & 67 \\
\hline 11 & $34 k$ & Toluene $^{b)}$ & 24 & 20 & 80 \\
\hline 12 & 341 & Benzene & 1 & 77 & - \\
\hline
\end{tabular}

a) The reaction time of Step 1 was $4 \mathrm{~h} . \quad$ b) Degassed. c) $10 \mathrm{~mol} \%$ of $\mathbf{E}$ was employed. d) $20 \mathrm{~mol} \%$ of $\mathbf{E}$ was employed.

Table 15. Isomerization and Cycloisomerization of Diene 34a

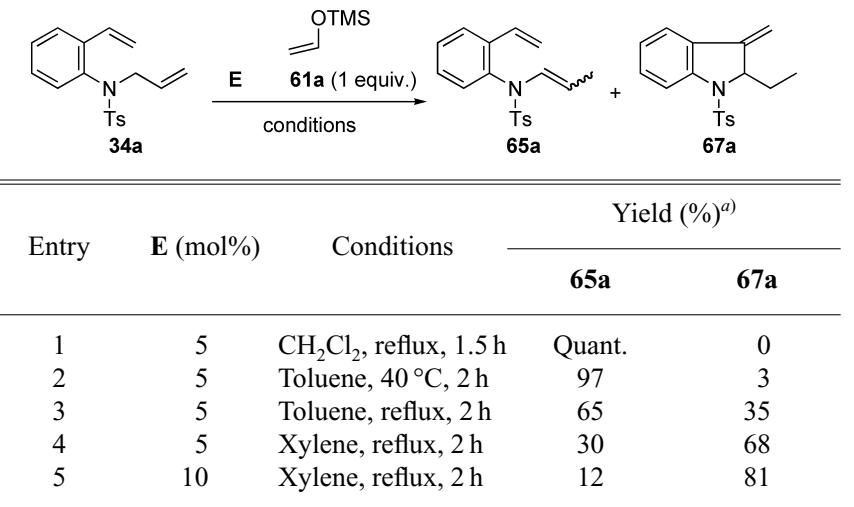

a) Yields were estimated by ${ }^{1} \mathrm{H}-\mathrm{NMR}$ spectroscopy.
Table 16. Cycloisomerization: Substituent Effect on Nitrogen
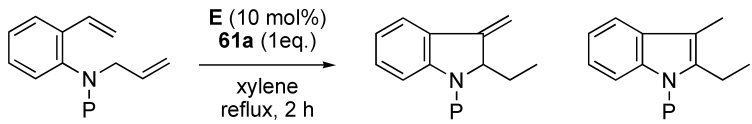

34a: Ts, 34m: Ac, 34n: Bz

34o: Boc, 34p: $\mathrm{Cbz}$

34q: Ms

67

68

\begin{tabular}{ccc}
\hline \hline Entry & Substrate & $\begin{array}{c}\text { Yield (\%) } \\
\mathbf{6 7} \text { and } \mathbf{6 8}(\text { ratio of } \mathbf{6 7 / 6 8})\end{array}$ \\
\hline 1 & $\mathbf{3 4 a}$ & $81(100 / 0)$ \\
2 & $\mathbf{3 4 m}$ & $69(57 / 43)$ \\
3 & $\mathbf{3 4 n}$ & $86(86 / 14)$ \\
4 & $\mathbf{3 4 0}$ & $92(84 / 16)$ \\
5 & $\mathbf{3 4 p}$ & $99(79 / 21)$ \\
6 & $\mathbf{3 4 q}$ & $86^{a)}(100 / 0)$
\end{tabular}

a) 3 eq of 61a was used.

Table 17. Synthesis of Indoline from $\mathbf{3 4}$

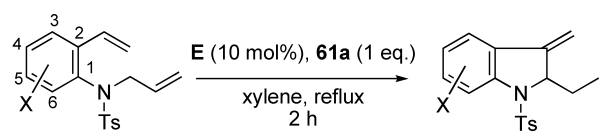

34a: H, 34b: 6-OMe, 34c: 5-OMe

34d: 4-OMe, 34e: $3-O M e$

34f: 4,5,6-triOMe, 34g: 6-Cl

34h: 5-Cl, 34i: 4-Cl, 34j: 3-C

34k: 3-Me, 34l: 6-Me

\begin{tabular}{ccc}
\hline \hline Entry & Substrate & Yield (\%) \\
& & $\mathbf{6 7}$ \\
\hline 1 & $\mathbf{3 4 a}$ & 81 \\
2 & $\mathbf{3 4 b}$ & $0^{a)}$ \\
3 & $\mathbf{3 4 c}$ & 52 \\
4 & $\mathbf{3 4 d}$ & 24 \\
5 & $\mathbf{3 4}$ & 63 \\
6 & $\mathbf{3 4} \mathbf{f}$ & $0^{a)}$ \\
7 & $\mathbf{3 4 g}$ & $0^{a)}$ \\
8 & $\mathbf{3 4 h}$ & 78 \\
9 & $\mathbf{3 4 i}$ & 84 \\
10 & $\mathbf{3 4}$ & 78 \\
11 & $\mathbf{3 4 k}$ & 95 \\
12 & $\mathbf{3 4 l}$ & $0^{a)}$ \\
\hline
\end{tabular}

a) Enamide was obtained quantitatively.

Table 18. Cycloisomerization to Benzofuran Derivatives

Conditions: E (10 mol\%), 61a (1 eq), toluene, 2h, reflux. a) $62 \%$ of $\mathbf{6 9 d}$ was re-
covered. 
Table 19. Cycloisomerizarion of Dienes

Entry

Conditions: E (10 mol\%), 61a (1 eq), xylene, reflux, $2 \mathrm{~h}$.

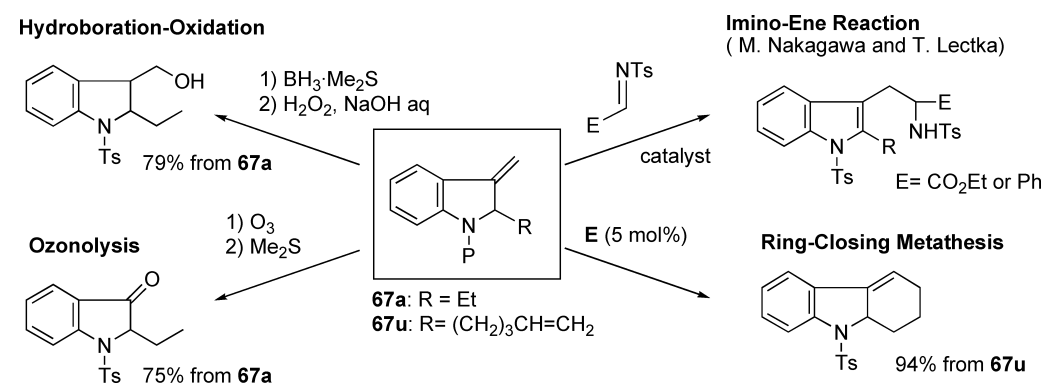

Chart 10. Reactions of 3-Methylene Group

gether with isomer $\mathbf{6 5 r}$ (entry 1). Isomerization of 34s gave $\mathbf{6 5 s}$ in $32 \%$ yield together with unreacted 34s (57\%) (entry 2 ). Likewise, the reaction of $34 t$ gave $65 t$ and $67 t$ in respective yields of $34 \%$ and $52 \%$ (entry 4 ). When enamides $(\mathbf{6 5 s}$, 65t) were subjected to the same reaction conditions, 67s and 67t were obtained in respective yields of $66 \%$ and $80 \%$ (entries 3,5), which shows that enamides $\mathbf{6 5}$ were intermediates for 67. The present cycloisomerization is quite general and useful for substrates with various functional groups.

Exomethylene in 3-methylene-2,3-dihydroindole is a very useful functional group for further transformation. Concerning this exomethylene group, Boger ${ }^{105)}$ and Sakamoto ${ }^{106)}$ previously reported hydroboration to introduce a hydroxymethyl group, and Nakagawa ${ }^{107)}$ and Lectka ${ }^{108)}$ prepared tryptophan and tryptamine derivatives using an imino-ene reaction. We also found that ozonolysis and RCM can be applied to the synthesis of indoxyl and carbazole derivatives, as shown in Chart 10. Therefore, the cycloisomerization of $\mathrm{N}$-allyl-ovinylaniline (34) is a new method for the synthesis of 2,3disubstituted indole derivatives.

Using our methods, substituted 1,2-dihydroquinoline, indole and 3-methylene-2,3-dihydroindole were prepared selectively from the common starting material $\mathrm{N}$-allyl-o-vinylaniline $\mathbf{3 4}$ and catalyst $\mathbf{E}$ by slight modification of the reaction conditions (Chart 11). These procedures address an important issue in diversity-oriented synthesis. ${ }^{109)}$

1.2.3. Actual Active Species of Olefin Isomerization and Cycloisomerization: All of the above methods for heterocy-

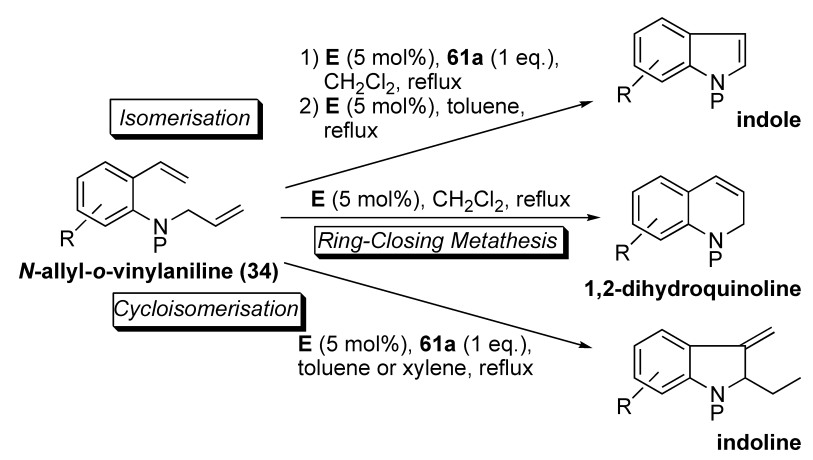

Chart 11. Diversity-Oriented Synthesis of Heterocycles

cles, including RCM of diene, isomerization of terminal olefin and cycloisomerization of diene, were easily carried out using an argon balloon and the standard Schlenck technique. In the isomerization of alkenes under our reaction conditions, the generation of $\mathrm{RuH}$ species should be a key step. Hence, we initially attempted to determine the structure of actual active ruthenium species, for the isomerization of terminal olefin as well as the cycloisomerization of diene, under various conditions using Schlenck technique. ${ }^{22)}$ However, strong support for our working hypothesis came from the reaction performed in a glovebox, which kept the oxygen and moisture concentrations below $1 \mathrm{ppm}$. We finally found that the reaction of $\mathbf{E}$ with $\mathbf{6 1 a}$ gave ruthenium hydride (A) in quantitative yield (Chart 12). Although this catalyst was 


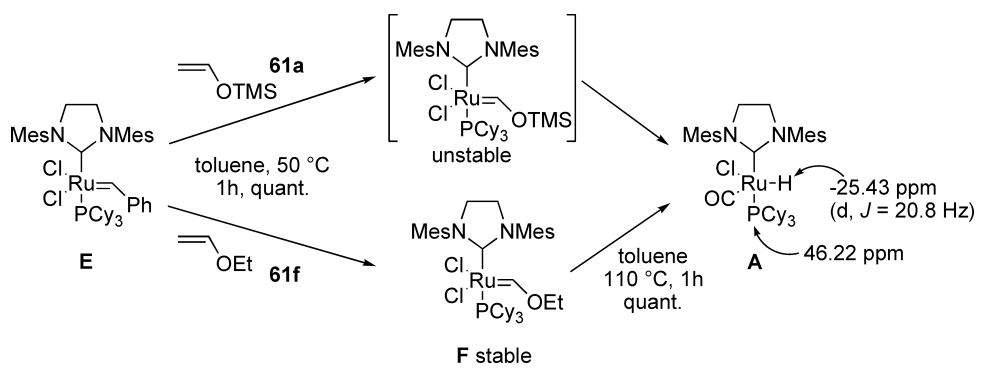

Chart 12. Quantitative Conversion of $\mathbf{E}$ to $\mathbf{A}$

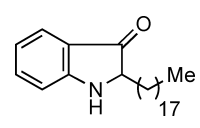

Fig. 6. Reported Structure of Fistulosin

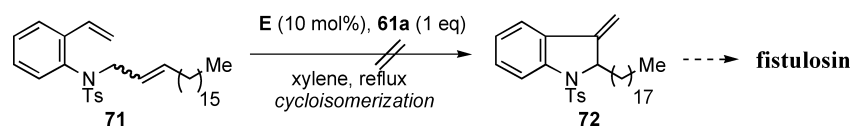

Chart 13. Initial Approach to Fistulosin

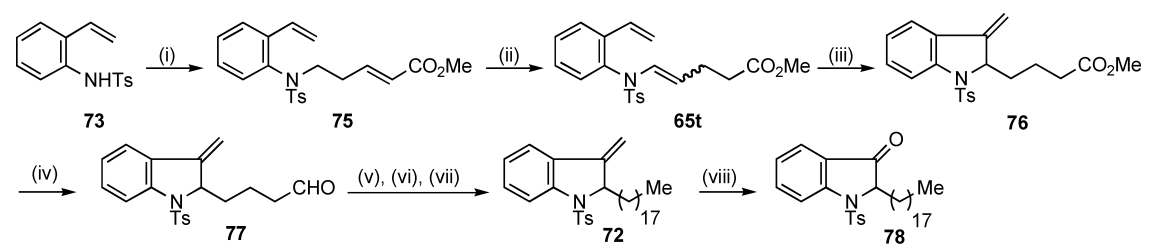

Reagents and conditions: (i) (E)-HO(CH$)_{2} \mathrm{CH}=\mathrm{CHCO}_{2} \mathrm{Me}$ (74), DEAD, $\mathrm{PPh}_{3}$, THF, rt, $4 \mathrm{~h}$, 99\%; (ii) RuClH(CO) $\left(\mathrm{PPh}_{3}\right)_{3}$, toluene, reflux, $23 \mathrm{~h}, 83 \%$; (iii) $\mathbf{E}(10$ mol\%), 61a (1 eq.), xylene, reflux, $2 \mathrm{~h}, 87 \%$; (iv) DIBAL, toluene, $-78{ }^{\circ} \mathrm{C}, 20 \mathrm{~min}, 87 \%$; (v) $\mathrm{BrMg}\left(\mathrm{CH}_{2}\right)_{13} \mathrm{Me}$, THF, $0{ }^{\circ} \mathrm{C}, 20$ min, $93 \%$; (vi) $\mathrm{MsCl}, \mathrm{Et}_{3} \mathrm{~N}$, DMAP, $\mathrm{CH}_{2} \mathrm{Cl}_{2}$, rt, $30 \mathrm{~min}, 86 \%$; (vii) $\mathrm{NaBH}_{4}, \mathrm{HMPA}, 50{ }^{\circ} \mathrm{C}, 2 \mathrm{~h}$, $71 \%$; (viii) $\mathrm{O}_{3}, \mathrm{CH}_{2} \mathrm{Cl}_{2},-78{ }^{\circ} \mathrm{C}, 15 \mathrm{~min}$, then $\mathrm{PPh}_{3}$, rt, $2 \mathrm{~h}, 70 \%$.

Chart 14. Synthesis of $N$-Tosyl-2-octadecyl-3-indolinone (78)

easily decomposed under aerobic conditions, it could be stored without any decomposition if kept in a glovebox. Dinger and Mol reported the preparation of $\mathbf{A}$ from another ruthenium hydride $\left(\mathrm{RuClH}(\mathrm{CO})\left(\mathrm{PCy}_{3}\right)_{2}\right) .{ }^{110)}$ Grubbs reported that $\mathbf{A}$ is generated by the partial decomposition of $\mathbf{E}$ in $\mathrm{MeOH} .{ }^{111)}$ However, neither method could give $\mathbf{A}$ with high purity. Our method for converting ruthenium carbene complex to ruthenium hydride complex is general and efficient because of its mildness and the high volatility of side products. In addition, this is the first example to show that $\mathbf{A}$ can efficiently catalyze the isomerization of terminal olefins and the cycloisomerization of dienes.

When $\mathbf{E}$ was reacted with $\mathbf{6 1 f}$ in toluene $(0.01 \mathrm{M})$ at $50^{\circ} \mathrm{C}$ for $1 \mathrm{~h}$, Fischer carbene catalyst (F) was obtained quantitatively, as reported by Grubbs. ${ }^{111)}$ Heating of $\mathbf{F}$ in toluene at $110^{\circ} \mathrm{C}$ gave $\mathbf{A}$ quantitatively. The presence of excess $61 \mathrm{f}$ did not affect the conversion of $\mathbf{F}$ to $\mathbf{A}$. At the same time, $\mathbf{F}$ has RCM activity ${ }^{111}$ but does not have isomerization or cycloisomerization activity. Therefore, in our reaction system (selective isomerization of terminal olefin and cycloisomerization of $\alpha, \omega$-diene), $\mathbf{6 1 f}$ interferes with $\mathbf{E}$ from reacting with terminal olefin or $\alpha, \omega$-diene and efficiently converts $\mathbf{E}$ to $\mathbf{A}$ through $\mathbf{F}$. We found strong evidence for the generation of RuH complex (A) in pure form.

1.2.4. Synthesis of the Putative Structure of Fistulosin Using Cycloisomerization as a Key Step ${ }^{27)}$ : Although the selective and catalytic cycloisomerizations of dienes, in which a new ring is formed without the loss of carbon units, are highly atom-economical reactions, the application of this reaction to the synthesis of natural products or pharmaceuti- cally useful compounds has not been reported because of limitations regarding the range of substrates and the tolerance of functional groups. Hence, we decided to synthesize the reported structure of fistulosin using our cycloisomerization of diene as a key step.

The antifungal indole fistulosin was isolated from the root of Welsh onion (Allium fistulosum L.) by Tomita's group in 1999 (Fig. 6). ${ }^{112}$ ) Vegetables in the Allium species are known to be rich in flavonoids and alk(en)yl cysteine sulfoxides, which have perceived benefits for human health. ${ }^{113)}$ Since the late 1980 s, biologically active products in Allium species have been investigated and the isolation of nematicidal and antibacterial agents has been reported by Tada's group. ${ }^{114)}$ Furthermore, Tomita's group reported the isolation of the new alkaloid fistulosin, which exhibited antifungal activities against the wilt-producing fungi Fusarium oxysporum. ${ }^{112)}$ In agriculture, antifungal agents isolated from natural products, such as fistulosin, are expected to be useful due to their safety toward animals, humans and ecosystems.

Initially, we planned to synthesize the key intermediate, which has an octadecyl group at the 2-position of the indoline core, from $o$-vinylaniline derivative 71 by ruthenium-catalyzed cycloisomerization. Unfortunately, however, the reaction of 71 in the presence of catalyst $\mathbf{E}$ and 61a did not provide the desired cyclized product at all, but rather gave a complex mixture of regioisomers, which were produced by olefin migration of the nonadecenyl side chain (Chart 13).

Therefore, we next chose the enamide $\mathbf{6 5 t}$ as a substrate for cycloisomerization (Chart 14). This substrate was expected to efficiently undergo our cycloisomerization, and an 
ester group was used for subsequent extension of the alkyl chain. The preparation of $\mathbf{6 5 t}$ began with the Mitsunobu reaction of readily available $\mathbf{7 3}$ with alcohol $\mathbf{7 4}$, and treatment of 75 with $\mathrm{RuClH}(\mathrm{CO})\left(\mathrm{PPh}_{3}\right)_{3}{ }^{115-118)}(10 \mathrm{~mol} \%)$ provided enamide $65 \mathbf{t}$ in $83 \%$ yield. With substrate $\mathbf{6 5 t}$ in hand, cycloisomerization of $\mathbf{6 5 t}$ in the presence of Grubbs catalyst $\mathbf{E}$ $(10 \mathrm{~mol} \%)$ and 61a (1 eq) in refluxing toluene was carried out and the expected product $\mathbf{7 6}$ was obtained as a stable colorless crystal in $87 \%$ yield. Installation of a tetradecyl group was achieved through a four-step procedure. Cyclized product 76 was reduced with DIBAL to give aldehyde 77, and treatment of $\mathbf{7 7}$ with Grignard reagent gave the secondary alcohol in $93 \%$ yield. Mesylation of the hydroxy group followed by reduction of the mesylate with $\mathrm{NaBH}_{4}$ gave indoline 72, which was converted to 3 -indolinone $\mathbf{7 8}$ by ozonolysis. Finally, treatment of $\mathbf{7 8}$ with conc. $\mathrm{H}_{2} \mathrm{SO}_{4}$ at $0^{\circ} \mathrm{C}^{119)}$ gave the deprotected product 79a quantitatively in crude form (Chart 15). 3-Indolinone 54a was pure and stable enough to characterize the structure by spectral analyses. However, fur-

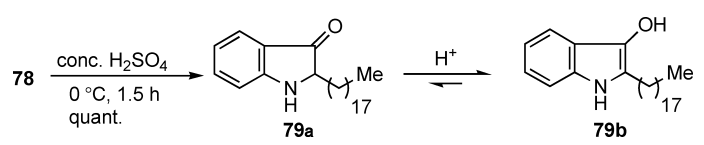

Chart 15. Deprotection and Tautomerization

Table 20. Comparison of Natural Fistulosin, 79a, 79b and 80 ther purifications of 79a by column chromatography or recrystallization were unsuccessful, even though we used the same procedure reported by Tomita, since 79a was gradually tautomerized to more thermodynamically stable 3-hydroxyindole 79b in solution. ${ }^{120-122)}$

Next, we compared the spectral data of 79a to those reported for natural fistulosin (Table 20). The IR spectrum of synthetic compound 79a revealed a strong band at $1675 \mathrm{~cm}^{-1}$, which was similar to the reported data $\left(1684 \mathrm{~cm}^{-1}\right)$, and the reported characteristic mass peak at $133\left[\mathrm{M}-\mathrm{C}_{18} \mathrm{H}_{36}{ }^{+}\right]$was also observed in the spectrum of 79a. On the other hand, the ${ }^{1} \mathrm{H}$-NMR spectra showed some remarkable differences. For our synthetic 79a, the chemical shift of the methine proton at the 2-position was observed at $3.75 \mathrm{ppm}$, in contrast to $2.44 \mathrm{ppm}$ reported by Tomita's group. In addition, conspicuous differences were seen in the ${ }^{13} \mathrm{C}$-NMR spectra. For example, the chemical shift of the carbonyl carbon of our sample was observed at $202.7 \mathrm{ppm}$, in contrast to the reported value of $171.5 \mathrm{ppm}$. Overall, the spectral data supported the structure of 79a. Thus, we concluded that the spectral data of 79a did not agree with those reported for fistulosin.

We next compared the spectral data of the more stable tautomer 79b and oxindole 80, which are other candidates for the natural product "fistulosin". Tautomerization of 79a pro-

\begin{tabular}{|c|c|c|c|c|}
\hline & Fistulosin (reported) & 79a (synthetic) & $\mathbf{7 9 b}$ (synthetic) & 80 (synthetic) \\
\hline State & $\begin{array}{l}\text { White crystal } \\
\mathrm{mp} 80-83^{\circ} \mathrm{C}\left(\mathrm{CHCl}_{3}\right)\end{array}$ & $\begin{array}{l}\text { Orange solid } \\
\mathrm{mp} 100-102^{\circ} \mathrm{C}\end{array}$ & $\begin{array}{l}\text { Yellow needle } \\
\text { mp } 107-108^{\circ} \mathrm{C} \\
(n \text {-hexane/AcOEt) }\end{array}$ & $\begin{array}{l}\text { Colorless prism } \\
\text { mp } 95-96^{\circ} \mathrm{C} \\
\text { (n-hexane) }\end{array}$ \\
\hline $\operatorname{IR}\left(\mathrm{cm}^{-1}\right)$ & $1684(\mathrm{CO})$ & $1675(\mathrm{CO})$ & $1674(\mathrm{OH})$ & $1698(\mathrm{CO})$ \\
\hline MS (EI) & $385\left(\mathrm{M}^{+}\right), 133$ & $385\left(\mathrm{M}^{+}\right), 161,133,84,18$ & $385\left(\mathrm{M}^{+}\right), 383,172,146,18$ & $385\left(\mathrm{M}^{+}\right), 146,18$ \\
\hline${ }^{1} \mathrm{H}-\mathrm{NMR}\left(\mathrm{CDCl}_{3}\right)$ & $\begin{array}{l}10.8(\text { br s, } 1 \mathrm{H}, \mathrm{NH}) \\
8.8(\mathrm{~d}, 1 \mathrm{H}, J=8.37 \mathrm{~Hz}, \mathrm{CH}) \\
8.1(\mathrm{~d}, 1 \mathrm{H}, J=8.12 \mathrm{~Hz}, \mathrm{CH}) \\
7.6(\mathrm{t}-\text { like, } 1 \mathrm{H}, \mathrm{CH}) \\
7.1(\mathrm{t}-\text { like, } 1 \mathrm{H}, \mathrm{CH}) \\
2.44(\mathrm{t}-\mathrm{like}, 1 \mathrm{H}, \mathrm{CH}) \\
1.74\left(\mathrm{~m}, 2 \mathrm{H}, \mathrm{CH}_{2}\right) \\
1.63\left(\mathrm{~m}, 2 \mathrm{H}, \mathrm{CH}_{2}\right) \\
1.4\left(\mathrm{~m}, 2 \mathrm{H}, \mathrm{CH}_{2}\right) \\
1.25\left(\text { br s, } 28 \mathrm{H} \mathrm{CH}_{2}\right) \\
0.88\left(\mathrm{t}-\mathrm{like}, 3 \mathrm{H}, \mathrm{CH}_{3}\right)\end{array}$ & $\begin{array}{l}7.61(\mathrm{~d}, 1 \mathrm{H}, J=7.9 \mathrm{~Hz}) \\
7.44(\mathrm{dd}, 1 \mathrm{H}, J=8.2,7.1 \mathrm{~Hz}) \\
6.88(\mathrm{~d}, 1 \mathrm{H}, J=8.6 \mathrm{~Hz}) \\
6.82(\mathrm{dd}, 1 \mathrm{H}, J=7.3,7.3 \mathrm{~Hz}) \\
4.70(\mathrm{brs}, 1 \mathrm{H}) \\
3.75(\mathrm{dd}, 1 \mathrm{H}, J=8.4,4.2 \mathrm{~Hz}) \\
1.83-1.96(\mathrm{~m}, 1 \mathrm{H}) \\
1.55-1.64(\mathrm{~m}, 1 \mathrm{H}) \\
1.25-1.40(\mathrm{~m}, 32 \mathrm{H}) \\
0.88(\mathrm{t}, 3 \mathrm{H}, J=6.8 \mathrm{~Hz})\end{array}$ & $\begin{array}{l}7.56(\mathrm{~d}, 1 \mathrm{H}, J=7.7 \mathrm{~Hz}) \\
7.49(\mathrm{ddd}, 1 \mathrm{H}, J=8.1,8.1,0.9 \mathrm{~Hz}) \\
6.95(\mathrm{~d}, 1 \mathrm{H}, J=8.2 \mathrm{~Hz}) \\
6.78(\mathrm{dd}, 1 \mathrm{H}, J=7.1,7.1 \mathrm{~Hz}) \\
6.08(\mathrm{br} \mathrm{s}, 1 \mathrm{H}) \\
1.84-1.90(\mathrm{~m}, 1 \mathrm{H}) \\
0.99-1.31(\mathrm{~m}, 35 \mathrm{H}) \\
0.88(\mathrm{t}, 3 \mathrm{H}, J=6.4 \mathrm{~Hz})\end{array}$ & $\begin{array}{l}8.63(\mathrm{br} \mathrm{s}, 1 \mathrm{H}) \\
7.22-7.26(\mathrm{~m}, 2 \mathrm{H}) \\
7.02(\mathrm{~d}, 1 \mathrm{H}, J=7.2 \mathrm{~Hz}) \\
6.91(\mathrm{br} \mathrm{m}, 1 \mathrm{H}) \\
3.47(\mathrm{br} \mathrm{m}, 1 \mathrm{H}) \\
1.96(\mathrm{br} \mathrm{m}, 2 \mathrm{H}) \\
1.23-1.41(\mathrm{~m}, 32 \mathrm{H}) \\
0.88(\mathrm{t}, 3 \mathrm{H}, J=6.8 \mathrm{~Hz})\end{array}$ \\
\hline${ }^{13} \mathrm{C}-\mathrm{NMR}\left(\mathrm{CDCl}_{3}\right)$ & $\begin{array}{l}171.5(\mathrm{~s}) \\
142.5(\mathrm{~s}) \\
135.8(\mathrm{~d}) \\
131.9(\mathrm{~d}) \\
122.7(\mathrm{~d}) \\
120.7(\mathrm{~d}) \\
113.7(\mathrm{~s}) \\
38.9(\mathrm{~s}) \\
32.1(\mathrm{~s}) \\
29.05-29.92(\mathrm{~m}) \\
25.9(\mathrm{~d}) \\
23.4(\mathrm{~s}) \\
14.3(\mathrm{~s})\end{array}$ & $\begin{array}{r}202.74 \\
161.31 \\
136.94 \\
124.49 \\
121.47 \\
118.85 \\
112.56 \\
64.25 \\
32.04 \\
31.90 \\
29.34-29.68(\mathrm{~m}) \\
25.80 \\
22.67 \\
14.10\end{array}$ & $\begin{array}{r}204.57 \\
162.00 \\
138.06 \\
124.16 \\
121.54 \\
118.27 \\
111.97 \\
72.51 \\
32.00 \\
31.94 \\
29.33-29.78(\mathrm{~m}) \\
22.95 \\
22.70 \\
14.13\end{array}$ & $\begin{array}{r}180.73 \\
141.57 \\
129.91 \\
127.72 \\
124.10 \\
122.17 \\
109.66 \\
46.11 \\
31.90 \\
30.53 \\
29.56-29.67(\mathrm{~m}) \\
29.34 \\
25.77 \\
22.67 \\
14.10\end{array}$ \\
\hline
\end{tabular}


ceeded smoothly in an acidic medium, such as aq. $\mathrm{HCl}$ or $\mathrm{H}_{2} \mathrm{SO}_{4}$, to give 79b, which could be purified by recrystallization from $n$-hexane/AcOEt. Although the crystals of $79 \mathrm{~b}$ were not suitable for X-ray analysis, other spectra, including 2D-NMR spectra $\left({ }^{1} \mathrm{H}-{ }^{1} \mathrm{H}\right.$ COSY, HMBC and HMQC), unambiguously confirmed the structure of 79b. Oxindole 80 was synthesized by the procedures reported by Overman and co-workers. ${ }^{123)}$ However, the spectral data of both $\mathbf{7 9 b}$ and $\mathbf{8 0}$ were also not consistent with those reported for fistulosin (Table 20). Further investigations are necessary to elucidate the structure of fistulosin.

\section{Development of Palladium Catalyst Supported on GaAs(001): B}

Organopalladium catalysts are very important in organic chemistry and widely used in the synthesis of biologically active compounds. ${ }^{124,125)}$ The Heck reaction has received considerable attention because it offers a reliable method for carbon-carbon bond formations. ${ }^{126,127)}$ Like many organic reactions using organometallic reagents and catalysts, the standard procedure under homogeneous conditions suffers from wasted noble metals or catalytically active metals which are difficult to recover and lost in aqueous work-up. With regard to green chemistry, heterogeneous organometallic catalysts are favored and currently being extensively studied. ${ }^{128-132)}$ However, most of these systems do not give as high a level of activity as homogeneous catalysts. Recently, it has been reported that some heterogeneous catalysts showed a higher activity than homogeneous ones, and the mechanism was studied in detail. ${ }^{133,134)}$

We have been aiming at the development of more practical heterogeneous catalysts, which should be active, leach-free and easy to handle, and reported an entirely novel organopalladium catalyst supported on a semiconductor surface, $\mathrm{GaAs}(001)$, terminated by a sulfur atom layer using molecular beam epitaxy $(\mathrm{MBE})^{135)}$ or ammonium sulfide solution (Fig. 7). ${ }^{136)}$ To the best of our knowledge, no one has reported a semiconductor that is capable of supporting an organometallic catalyst. We expected this new material to amplify the recyclability, or activate differently the aryl halides. In these reports, we have presented the following

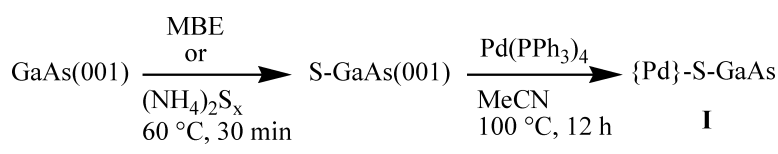

Fig. 7. Preparation of Three-Phase Catalyst, $\{\mathrm{Pd}\}-\mathrm{S}-\mathrm{GaAs}(001)$, Catalyst I findings: 1) a $\{\mathrm{Pd}\}-\mathrm{S}-\mathrm{GaAs}(001)$ plate catalyzed the Heck reaction more efficiently than $\mathrm{Pd}\left(\mathrm{PPh}_{3}\right)_{4}$, which is widely used as a homogeneous catalyst, and could be reused at least 10 times, 2) inactivated $\{\mathrm{Pd}\}-\mathrm{S}-\mathrm{GaAs}(001)$ could be revitalized by further treatment with $\operatorname{Pd}\left(\mathrm{PPh}_{3}\right)_{4}$, and 3) sulfur-termination in this catalyst was important for stability of this catalyst. ${ }^{135,136)}$

Here, we present a method for preparing $\{\mathrm{Pd}\}-\mathrm{S}$ GaAs(001), which is drastically improved in both catalytic activity and stability. Some chemical and physical properties of the catalyst were elucidated using X-ray photoelectron spectroscopy (XPS), and scanning electron microscopy (SEM). Furthermore, experiments were carried out in order to attempt identification of the real active Pd-species.

As we have previously reported, ${ }^{136)}\{\mathrm{Pd}\}-\mathrm{S}-\mathrm{GaAs}(001)$, which is named catalyst $\mathbf{I}$, was prepared by a three-step procedure, $\left(\mathrm{NH}_{4}\right)_{2} \mathrm{~S}_{\mathrm{x}}$ treatment (aqueous solution, $60^{\circ} \mathrm{C}$, $30 \mathrm{~min})$, and $\mathrm{Pd}$ adsorption $\left(\mathrm{Pd}\left(\mathrm{PPh}_{3}\right)_{4}, 7.2 \mathrm{~mm}, 100^{\circ} \mathrm{C}, 12 \mathrm{~h}\right)$ followed by washing at room temperature with acetonitrile $(\mathrm{MeCN})$. This catalyst A could be used for the Heck reaction of iodobenzene (81a) and methyl acrylate (82a) over 10 times (Chart 16). The chemical yield of the 10th run, however, was only $24 \%$ and the average chemical yield of 10 runs was $56 \%$ (Table 21 , entry 1 ). To identify a more reactive catalyst, we surveyed the sources of Pd. Catalysts II-V were prepared by the same method as catalyst I except for the source of $\mathrm{Pd}$, and then repeatedly subjected to the Heck reaction as shown in Chart 15 . The results are summarized in Table 21. Catalyst II, prepared with $\mathrm{PdCl}_{2}$, showed almost no activity (entry 2). Catalysts III and IV, prepared with $\mathrm{Pd}(\mathrm{acac})_{2}$ and $\mathrm{Pd}(\mathrm{MeCN})_{2} \mathrm{Cl}_{2}$, respectively, were unstable and lost most of their catalytic activity before the 7th run (entries 3 , 4). Catalyst $\mathbf{V}$, prepared with $\operatorname{Pd}(\mathrm{dba})_{2}$, retained its activity until the 10th run, but its activity was lower than that of catalyst $\mathbf{I}$ (entry 5). In contrast, catalyst $\mathbf{V}$, prepared with $\mathrm{Pd}(\mathrm{OAc})_{2}$, had much higher activity than catalyst $\mathbf{I}$ and the coupling product was obtained in $79 \%$ yield in the 10 th run (entry 6). Therefore, $\mathrm{Pd}(\mathrm{OAc})_{2}$ is the best source of $\mathrm{Pd}$ among those tested for preparing $\{\mathrm{Pd}\}-\mathrm{S}-\mathrm{GaAs}(001)$.

Next, we examined heated-washing conditions after $\mathrm{Pd}$ adsorption, since it is possible that excess $\mathrm{Pd}$ on the

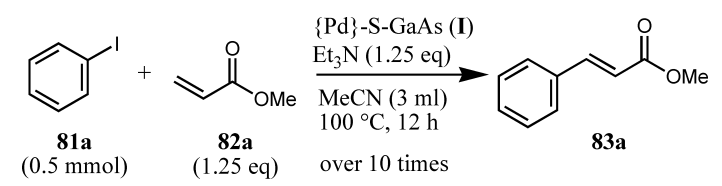

Chart 16. Heck Reaction

Table 21. Effect of Pd Sources in Pd Adsorption

\begin{tabular}{|c|c|c|c|c|c|c|c|c|c|c|c|c|c|}
\hline \multirow{2}{*}{ Entry } & \multirow{2}{*}{ Cat. } & \multirow{2}{*}{ Pd source } & \multicolumn{11}{|c|}{ Yield of $83 \mathbf{a}(\%)^{a)}$} \\
\hline & & & $1 \mathrm{st}$ & 2 nd & $3 \mathrm{rd}$ & 4 th & 5 th & 6th & 7 th & 8th & 9th & 10th & ave. \\
\hline 1 & I & $\mathrm{Pd}\left(\mathrm{PPh}_{3}\right)_{4}$ & 93 & 87 & 71 & 72 & 57 & 54 & 35 & 37 & 25 & 24 & 56 \\
\hline 2 & II & $\mathrm{PdCl}_{2}$ & 1 & 1 & 0 & - & - & - & - & - & - & - & - \\
\hline 3 & III & $\operatorname{Pd}(\mathrm{acac})_{2}$ & 51 & 31 & 14 & 15 & 10 & 12 & 1 & - & - & - & - \\
\hline 4 & IV & $\mathrm{Pd}\left(\mathrm{CH}_{3} \mathrm{CN}\right)_{2} \mathrm{Cl}_{2}$ & 43 & 8 & 1 & 0 & 1 & - & - & - & - & - & - \\
\hline 5 & $\mathbf{V}$ & $\operatorname{Pd}(\mathrm{dba})_{2}$ & 74 & 66 & 31 & 46 & 12 & 9 & 5 & 1 & 1 & 4 & 25 \\
\hline 6 & VI & $\mathrm{Pd}(\mathrm{OAc})_{2}$ & 100 & 99 & 91 & 98 & 97 & 88 & 81 & 72 & 71 & 79 & 88 \\
\hline
\end{tabular}

a) Isolated yields. 
Table 22. Effects of Washing Conditions after Pd Adsorption

\begin{tabular}{|c|c|c|c|c|c|c|c|c|c|c|c|c|c|c|}
\hline \multirow{2}{*}{ Entry } & \multirow{2}{*}{ Cat. } & \multirow{2}{*}{$\begin{array}{l}\text { Pd } \\
\text { source }\end{array}$} & \multirow{2}{*}{$\begin{array}{c}\text { Heated } \\
\text { washing }\end{array}$} & \multicolumn{10}{|c|}{ Yield of 83a $(\%)^{a)}$} & \multirow[b]{2}{*}{ ave } \\
\hline & & & & $1 \mathrm{st}$ & 2 nd & $3 \mathrm{rd}$ & 4 th & 5 th & 6th & 7 th & 8th & 9th & 10th & \\
\hline 1 & I & $\mathrm{Pd}\left(\mathrm{PPh}_{3}\right)_{4}$ & No & 93 & 87 & 71 & 72 & 57 & 54 & 35 & 37 & 25 & 24 & 56 \\
\hline 2 & VII & $\mathrm{Pd}\left(\mathrm{PPh}_{3}\right)_{4}$ & Yes & 90 & 55 & 67 & 66 & 57 & 54 & 46 & 43 & 43 & 39 & 56 \\
\hline 3 & VI & $\mathrm{Pd}(\mathrm{OAc})_{2}$ & No & 100 & 99 & 91 & 98 & 97 & 88 & 81 & 72 & 71 & 79 & 88 \\
\hline 4 & VIII & $\mathrm{Pd}(\mathrm{OAc})_{2}$ & Yes & 96 & 100 & 91 & 93 & 98 & 100 & 96 & 99 & 98 & 95 & 97 \\
\hline
\end{tabular}

a) The yields were determined by NMR analysis.

Table 23. Optimization of Heated-Washing Conditions

\begin{tabular}{|c|c|c|c|c|c|c|c|c|c|c|c|c|c|c|}
\hline \multirow{2}{*}{ Entry } & \multirow{2}{*}{ Cat. } & \multicolumn{2}{|c|}{ Heated washing } & \multicolumn{10}{|c|}{ Yield of $83 \mathbf{a}(\%)^{a)}$} & \multirow[b]{2}{*}{ ave. } \\
\hline & & Solvent & $T\left({ }^{\circ} \mathrm{C}\right)^{b)}$ & $1 \mathrm{st}$ & $2 \mathrm{nd}$ & $3 \mathrm{rd}$ & 4 th & 5 th & 6 th & 7 th & 8 th & 9th & 10th & \\
\hline 1 & VIII & $\mathrm{MeCN}$ & 100 & 96 & 100 & 91 & 93 & 98 & 100 & 96 & 99 & 98 & 95 & 97 \\
\hline 2 & IX & Toluene & 100 & 98 & 96 & 92 & 82 & 82 & 63 & 55 & 48 & 62 & 63 & 74 \\
\hline 3 & $\mathbf{X}$ & DMF & 100 & 98 & 86 & 95 & 89 & 80 & 84 & 75 & 77 & 69 & 70 & 82 \\
\hline 4 & XI & DMSO & 100 & 88 & 78 & 64 & 38 & 21 & 17 & 16 & 12 & 13 & 14 & 36 \\
\hline 5 & XII & DMF & 135 & 70 & 80 & 78 & 58 & 52 & 49 & 43 & 32 & 31 & 31 & 52 \\
\hline 6 & XIII & Toluene & 135 & 95 & 93 & 93 & 97 & 94 & 91 & 91 & 90 & 90 & 85 & 92 \\
\hline 7 & XIV & Xylene & 135 & 96 & 100 & 99 & 98 & 100 & 91 & 96 & 97 & 92 & 91 & 96 \\
\hline 8 & XV & Xylene & 150 & 99 & 99 & 100 & 97 & 99 & 91 & 97 & 94 & 92 & 86 & 95 \\
\hline
\end{tabular}

a) The yields in entry 1 were determined by NMR analysis. The yields in entries 2 to 8 were determined by HPLC analysis. b) Bath temperature.

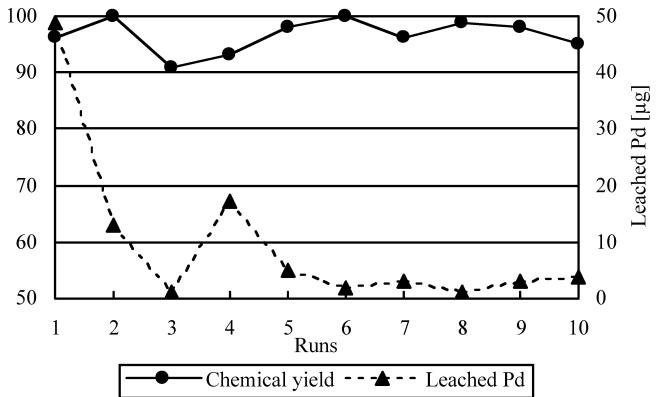

Fig. 8. Chemical Yield and Amount of Leached Pd Using Catalyst VIII

surface, which is not bound to sulfur, deactivate $\{\mathrm{Pd}\}-\mathrm{S}$ GaAs(001) by forming a less active or inactive colloidal Pd species. ${ }^{137-139)}$ Hence, catalysts $\mathbf{V}$ and VIII were prepared by a new three-step procedure, which consisted of $\left(\mathrm{NH}_{4}\right)_{2} \mathrm{~S}_{\mathrm{x}}$ treatment $\left(60^{\circ} \mathrm{C}, 30 \mathrm{~min}\right), \mathrm{Pd}$ adsorption $\left(\mathrm{Pd}\left(\mathrm{PPh}_{3}\right)_{4}\right.$ or $\left.\operatorname{Pd}(\mathrm{OAc})_{2}, 100^{\circ} \mathrm{C}, 12 \mathrm{~h}\right)$, and heated-washing in refluxing $\mathrm{MeCN}$. The catalysts were subjected to the same Heck reaction (Chart 15) over 10 times, respectively. As shown in Table 22, the activity of catalyst VII, which was prepared with $\mathrm{Pd}\left(\mathrm{PPh}_{3}\right)_{4}$ followed by heated-washing, was the same as that of catalyst $\mathbf{I}$, which was not treated by heated-washing. In contrast, catalyst VIII, which was prepared with $\mathrm{Pd}(\mathrm{OAc})_{2}$, had higher activity than catalyst VI, that is, the catalytic activity of VIII did not decrease over 10 runs $(95 \%$, entry 4$)$, and the average chemical yield over 10 runs was $97 \%$.

We measured the amount of Pd that leached into the reaction solution after the Heck reaction using catalyst VIII by inductively coupled plasma mass spectrometry (ICP-Mass). Figure 8 summarizes the chemical yield of the product and the amount of leached Pd in each run. While the chemical yield was almost quantitative through 10 runs, the amount of leached Pd decreased after 4 uses. The amount of Pd leached

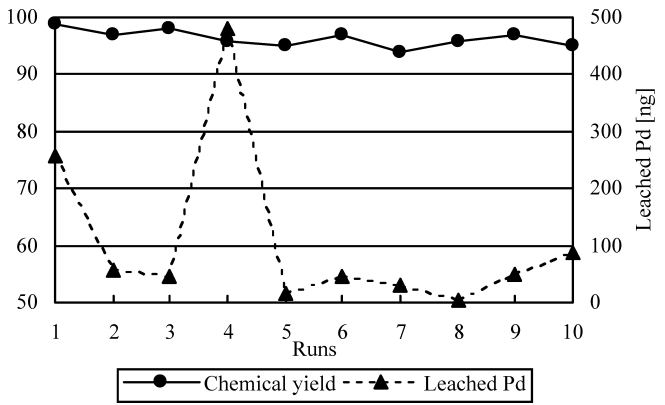

Fig. 9. Chemical Yield and Amount of Leached Pd Using Catalyst XIV Unit of leached Pd is ng not $\mu \mathrm{g}$.

after the 5 th run is a few $\mu \mathrm{g}$, less than $1.7 \mathrm{ppm}$. Considering that the amount of immobilized Pd after the 10th run is $125 \mu \mathrm{g}$, only trace amounts of Pd were leached after the 5th run.

Unfortunately, after several experiments, we found the reproducibility of the catalytic activity for catalyst VIII was poor. Hence, we optimized the heated-washing conditions. First, we carried out the heated-washing using some solvents (Table 23, entries 1-4). Among the solvents we examined, catalyst VIII, which had been washed in $\mathrm{MeCN}$ at $100^{\circ} \mathrm{C}$ (bath temperature), had the best catalytic activity. Next, we continued to examine the effect of solvent in heated-washing at higher temperature $\left(135^{\circ} \mathrm{C}\right.$, bath temperature). We found toluene can be another candidate for heated-washing, but its catalytic activity was lower than that of catalyst VIII (entry 6). In entry 7 , we carried out heated-washing in xylene at $135^{\circ} \mathrm{C}$. The activity of catalyst XIV was as high as that of catalyst VIII with good reproducibility and catalyst XIV kept its high activity through 10 runs (entry 7). When heatedwashing was carried out in xylene at $150{ }^{\circ} \mathrm{C}$, the activity of catalyst $\mathbf{X V}$ decreased slightly (entry 8 ).

When catalyst XIV was employed, ICP-Mass analysis in- 
dicated the amount of $\mathrm{Pd}$ that leached into the reaction mixture was an extremely low level in each run $(0.04-0.26 \mathrm{ppm}$, Fig. 9). These results suggested that heated-washing in noncoordinated solvent can prepare highly reactive and stable catalysts with good reproducibility and lower leaching, although further experiments are required to explain why these differences in catalytic activities appeared just by changing the solvent and temperature in heated-washing.

Next, to ascertain the scope and limitation of catalyst XIV, it was subjected to the Heck reaction of other substrates. The results are summarized in Tables 24 and 25. Bromobenzene (81b) and phenyl trifluoromethanesulfonate $(\mathbf{8 1 c})$, which are widely used as a substrate for the Heck reaction, ${ }^{140)}$ were totally inactive under our conditions (Table 24, entries 1, 2). In these cases, catalyst XIV, which was used over 5 runs, still possessed catalytic activity for the Heck reaction between 81 a and 82a, therefore, we assume that our catalyst could not undergo oxidative addition with $\mathbf{8 1 b}$ and $81 \mathrm{c}$ under these reaction conditions. When 2-, 3-, and 4-iodotoluene were used as substrates, the chemical yields of the corresponding product were varied depending on the position of the methyl group on the aromatic ring (entries 3-5). When 4iodoanisole $(\mathbf{8 1 g})$ was used as a substrate, the reaction proceeded, although the yields decreased gradually (entry 6).
When 4-bromo-1-iodobenzene $(\mathbf{8 1 h})$ was used, the reaction proceeded chemoselectively to give only 4-bromocinnamate, but the reactivity also gradually decreased (entries 7-9). In entries 10 and 11, the aryl iodides with electron-withdrawing groups at the para-position were used to yield the corresponding products at the 1 st run, however, after the 2 nd run, the chemical yields decreased drastically, and no reactivity was left after the 5th run. In entry 12, 1-iodonaphthalene, which is known for its occasional low activity, ${ }^{141)}$ was used as a substrate gave the corresponding product in excellent yield over 10 runs and the average yield was 94\%. The fact that the non- or de-activated aryl iodides react better than activated ones (entries 3-6 versus 8,9 ) might suggest that the use of the support modify slightly modified the reaction mechanism, or displaced the limiting step of the reaction from the oxidative addition of the aryl halide to $\operatorname{Pd}(0)$ to the reductive elimination to give the expected compound, although we do not have enough data to discuss this matter in detail at this stage.

When methyl vinyl ketone $(\mathbf{8 2} \mathbf{b})$ was used instead of $\mathbf{8 2} \mathbf{a}$, the chemical yield of the 1 st run was $76 \%,{ }^{142-148)}$ and almost the same chemical yield continued through 10 runs.

From these results, we found that our catalyst could catalyze only aryl iodides, and the catalytic activities were also

Table 24. Heck Reaction of Various Aryl Halides

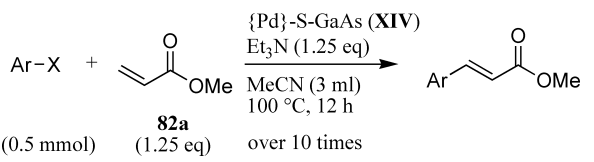

\begin{tabular}{|c|c|c|c|c|c|c|c|c|c|c|c|c|c|c|c|}
\hline \multirow{2}{*}{ Entry } & & \multicolumn{2}{|c|}{ Substrate $[\mathrm{Ar}-\mathrm{X}]$} & \multicolumn{12}{|c|}{ Yield of 83a $(\%)^{a}$} \\
\hline & & $\mathrm{Ar}$ & $\mathrm{X}$ & & $1 \mathrm{st}$ & 2 nd & $3 \mathrm{rd}$ & 4 th & 5 th & 6th & 7 th & 8 th & 9th & 10th & ave. \\
\hline 1 & 81b & $\mathrm{C}_{6} \mathrm{H}_{5}$ & $\mathrm{Br}$ & $\mathbf{8 3} \mathbf{a}^{b)}$ & 0 & 0 & $0^{c)}$ & $0^{d)}$ & $0^{e)}$ & - & - & - & - & - & $0^{f)}$ \\
\hline 2 & 81c & $\mathrm{C}_{6} \mathrm{H}_{5}$ & OTf & $83 \mathbf{a}^{b)}$ & 0 & 0 & $0^{c)}$ & $0^{d)}$ & $0^{e)}$ & - & - & - & - & - & $0^{f)}$ \\
\hline 3 & 81d & $2-\mathrm{MeC}_{6} \mathrm{H}_{4}$ & I & 83b & 98 & 90 & 94 & 81 & 72 & 63 & 52 & 49 & 43 & 36 & 68 \\
\hline 4 & $81 \mathrm{e}$ & $3-\mathrm{MeC}_{6} \mathrm{H}_{4}$ & I & $83 c$ & 100 & 100 & 100 & 72 & 62 & 56 & 59 & 47 & 46 & 38 & 68 \\
\hline 5 & $81 f$ & $4-\mathrm{MeC}_{6} \mathrm{H}_{4}$ & I & 83d & 100 & 100 & 100 & 100 & 100 & 100 & 100 & 100 & 98 & 96 & 99 \\
\hline 6 & $81 \mathrm{~g}$ & 4- $\mathrm{MeOC}_{6} \mathrm{H}_{4}$ & I & $83 e$ & 100 & 92 & 100 & 87 & 75 & 89 & 68 & 48 & 50 & 54 & 76 \\
\hline 7 & $81 \mathrm{~h}$ & $2-\mathrm{BrC}_{6} \mathrm{H}_{4}$ & I & $83 f$ & 92 & 71 & 80 & 57 & 65 & 58 & 36 & 28 & 28 & 25 & 54 \\
\hline 8 & $81 i$ & $3-\mathrm{BrC}_{6} \mathrm{H}_{4}$ & $\mathrm{I}$ & $83 \mathrm{~g}$ & 100 & 100 & 81 & 57 & 47 & 39 & 40 & 38 & 25 & 29 & 56 \\
\hline 9 & $81 \mathbf{j}$ & 4- $\mathrm{BrC}_{6} \mathrm{H}_{4}$ & I & $83 \mathrm{~h}$ & 98 & 81 & 67 & 56 & 65 & 49 & 42 & 41 & 38 & 42 & 58 \\
\hline 10 & $81 k$ & $4-\mathrm{NO}_{2} \mathrm{C}_{6} \mathrm{H}_{4}$ & $\mathrm{I}$ & $83 \mathbf{i}$ & 82 & 34 & 10 & 4 & 0 & - & - & - & - & - & $\left.26^{f}\right)$ \\
\hline 11 & 811 & 4- $\mathrm{MeC}(\mathrm{O}) \mathrm{C}_{6} \mathrm{H}_{4}$ & I & $\mathbf{8 3} \mathbf{j}^{g)}$ & 91 & 59 & 51 & 44 & 38 & - & - & - & - & - & $57^{f)}$ \\
\hline 12 & 84 & Xylene & I & 85 & 99 & 100 & 100 & 99 & 94 & 100 & 83 & 92 & 91 & 83 & 94 \\
\hline
\end{tabular}

a) Yields were determined by ${ }^{1} \mathrm{H}-\mathrm{NMR}$ spectra $\left(\mathrm{PhNO}_{2}(0.25 \mathrm{mmol})\right.$ was employed as an internal standard.). b) Yields were determined by HPLC analysis. $c$ ) Reaction time was $24 \mathrm{~h} . \quad d$ ) Reaction was carried out in toluene at $135^{\circ} \mathrm{C}$ (bath temperature) for $12 \mathrm{~h} . \quad$ e) Reaction was carried out in toluene at $135^{\circ} \mathrm{C}$ (bath temperature) for $24 \mathrm{~h} . \quad f$ ) Average yield through 1 to 5 runs. g) $0.50 \mathrm{mmol}$ of acetophenone was used as an internal standard.

Table 25. Heck Reaction of Methyl Vinyl Ketone

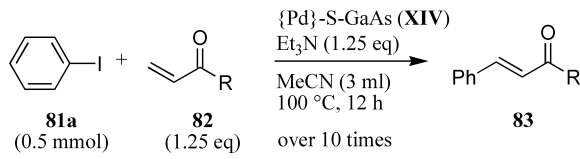

\begin{tabular}{|c|c|c|c|c|c|c|c|c|c|c|c|c|c|c|}
\hline \multirow{2}{*}{ Entry } & \multirow{2}{*}{\multicolumn{2}{|c|}{$\begin{array}{c}\text { Substrate } \\
(\mathbf{8 2}) \\
\text { R }\end{array}$}} & \multicolumn{12}{|c|}{ Yield of $83 \mathbf{a}(\%)^{a)}$} \\
\hline & & & & $1 \mathrm{st}$ & 2nd & $3 \mathrm{rd}$ & 4th & 5 th & 6 th & 7 th & 8th & 9th & 10th & ave. \\
\hline 1 & $82 a$ & $\mathrm{OMe}$ & $83 a$ & 96 & 100 & 99 & 98 & 100 & 91 & 96 & 97 & 92 & 91 & 96 \\
\hline 2 & $82 b$ & $\mathrm{Me}$ & $83 k$ & 76 & 80 & 79 & 78 & 77 & 76 & 72 & 75 & 74 & 71 & 76 \\
\hline
\end{tabular}

a) Yields were determined by ${ }^{1} \mathrm{H}-\mathrm{NMR}$ spectra $\left(\mathrm{PhNO}_{2}(0.25 \mathrm{mmol})\right.$ was employed as an internal standard.). 
influenced by the substituent on aryl iodides.

2.1. Catalysis Properties Based on the above discoveries, we investigated the characteristics of catalyst VIII in detail. First, the status of Pd on the surface both before and after these reactions was examined by XPS measurement ${ }^{149}$ ) of catalyst VIII using $\mathrm{Mg}$ ka radiation $($ K.E. $=1253 \mathrm{eV}$ ) in a separate ultra-high-vacuum chamber. The energy shift due to sample charging was corrected as the $\mathrm{C} 1 \mathrm{~s}$ peak is located at $285.0 \mathrm{eV}$. The XPS spectrum of catalyst $\mathrm{H}$ before the Heck reaction exhibited clear peaks of $\mathrm{Pd} 3 \mathrm{~d}$ core-level photoemission, indicating that the organopalladium was definitely immobilized as expected (spectrum I in Fig. 10). The peak width is slightly wider than that of metal Pd (not shown), suggesting a complex chemical environment and/or partial

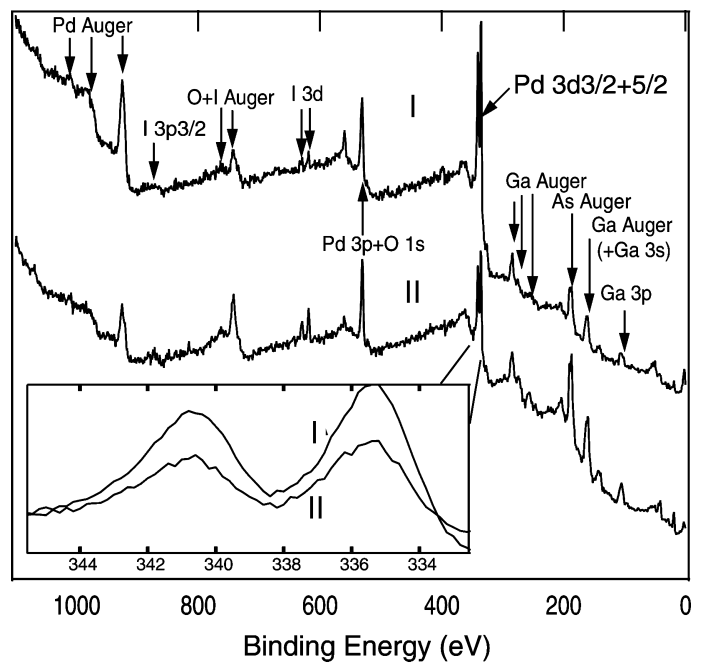

I: before Heck reaction

II: after Heck reaction (10 times)

Fig. 10. XPS Spectra of Catalyst VIII

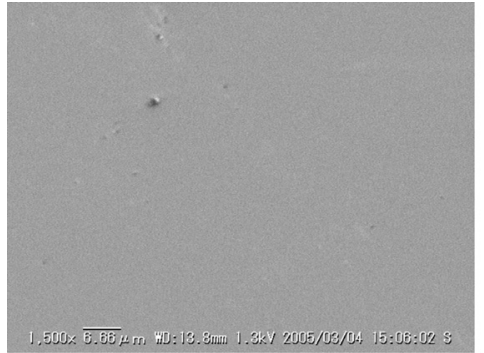

a. $\operatorname{GaAs}(001)$

(x 1,500)

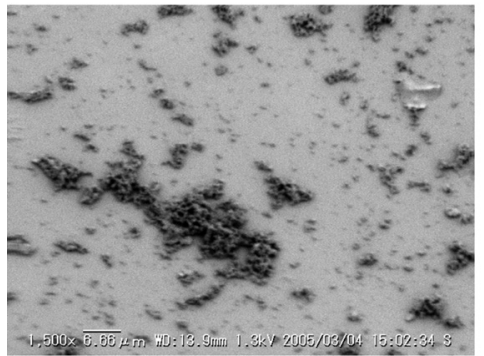

c. catalyst VIII after the Heck reaction (x 1,500) oxidation of $\mathrm{Pd}$. The binding energy of the $\mathrm{Pd} 3 \mathrm{~d} 5 / 2$ peak, $335.9 \mathrm{eV}$, is close to that of metal $\mathrm{Pd}, 335.0 \mathrm{eV}$, indicating that the valence of $\mathrm{Pd}$ is zero, ${ }^{150)}$ while that of the Pd source, $\mathrm{Pd}(\mathrm{OAc})_{2}$, is 2 . Even after repeated cycles of the Heck reaction, catalyst VIII showed almost the same $\mathrm{Pd} 3 \mathrm{~d}$ peaks (spectrum II in Fig. 10), suggesting that the oxidation state of the immobilized Pd did not change in the repeated Heck reactions.

Second, to obtain further information about the surface both before and after 10 runs of the Heck reaction, catalyst VIII was directly surveyed by SEM and compared to the GaAs(001) substrate. As shown in Fig. 11, catalyst VIII before the Heck reaction had a characteristic structure on $\operatorname{GaAs}(001)$ (b) and after 10 runs of the Heck reaction, the surface structure was obviously changed (c and d), although the catalytic activity showed no significant difference between the 1 st run and the 10th run of the Heck reaction.

2.2. Mechanistic Study Identification of the real catalyst is one of the important problems in the development of a novel heterogeneous catalyst. ${ }^{133,134)}$ First, we conducted a three-phase test. ${ }^{151,152)}$ This test can clarify which soluble or insoluble species is the real active catalyst by running a metal-catalyzed reaction in the presence of a substrate immobilized on polymer. We prepared the immobilized iodobenzene $(\mathbf{8 7})$ according to Davies' protocol, ${ }^{153)}$ and carried out the Heck reaction of $\mathbf{8 1 a}$ and $\mathbf{8 7}$ with $\mathbf{8 2 a}$ in the presence of $\{\mathrm{Pd}\}-\mathrm{S}-\mathrm{GaAs}$, catalyst XIV (Chart 17). After the reaction mixture was refluxed for $12 \mathrm{~h}$, the catalyst was removed. Then the reaction mixture was filtered. From the filtrate, $2 \%$ of coupling product 83a was obtained. The resin was treated with an excess amount of trifluoroacetic acid (TFA) at room temperature for $2 \mathrm{~h}$ to give $\mathbf{8 8}$ in $30 \%$ yield. As a control, we ran the Heck reaction of only 87 using $\{\mathrm{Pd}\}-\mathrm{S}-\mathrm{GaAs}$. In this case, the coupling product $\mathbf{8 8}$ was not obtained. Furthermore, using a homogeneous catalyst, $\mathrm{Pd}(\mathrm{OAc})_{2}$, the Heck reaction proceeded to give $\mathbf{8 8}$ in $62 \%$ yield.

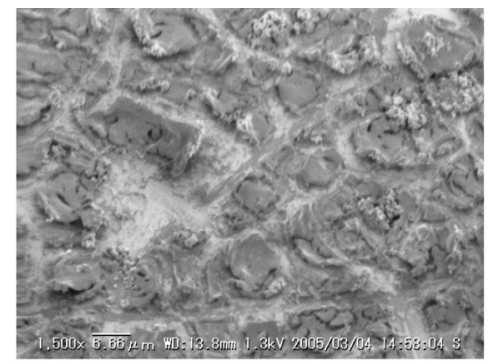

b. catalyst VIII before the Heck reaction (x 1,500)

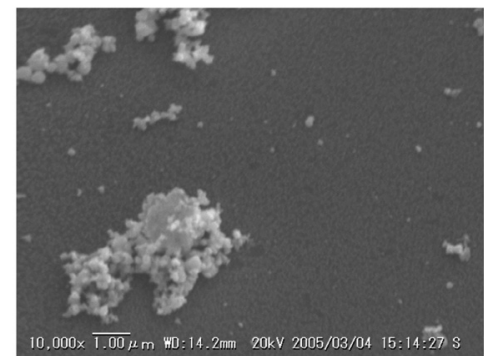

d. catalyst VIII after the Heck reaction (x 10,000)

Fig. 11. SEM Observation of Catalyst VIII 


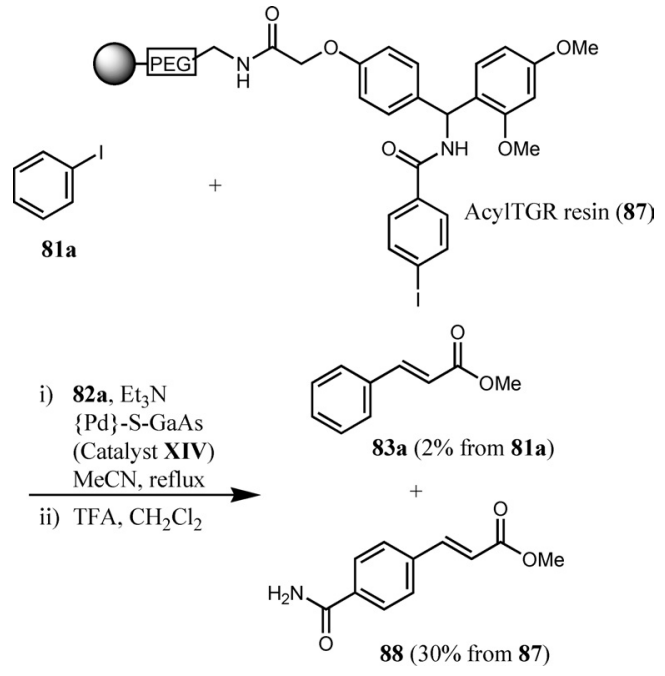

Chart 17. Three Phase Test

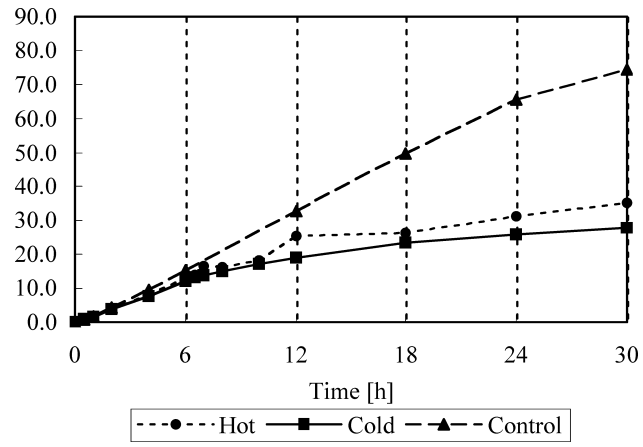

Fig. 12. Hot and Cold Filtration Tests

Next, we examined hot and cold filtration tests to see whether leached Pd species have catalytic activity for the Heck reaction. ${ }^{154)}$ A mixture of 81a, 82a, $\mathrm{Et}_{3} \mathrm{~N}$, and $\{\mathrm{Pd}\}-\mathrm{S}-$ $\mathrm{GaAs}$ in $\mathrm{MeCN}$ was refluxed for $6 \mathrm{~h}$ without stirring, and then the catalyst was removed from the 'hot' mixture. The yield of 83a was $13 \%$ in this step. The 'hot' solution was continuously refluxed without $\{\mathrm{Pd}\}-\mathrm{S}-\mathrm{GaAs}$. After $24 \mathrm{~h}$ (total time $30 \mathrm{~h}$ ), the yield of $\mathbf{8 3 a}$ was $35 \%$. In addition, a mixture of 81a, 82a, $\mathrm{Et}_{3} \mathrm{~N}$, and $\{\mathrm{Pd}\}-\mathrm{S}-\mathrm{GaAs}$ in $\mathrm{MeCN}$ was refluxed for $6 \mathrm{~h}$ without stirring. After the mixture was cooled to room temperature, the catalyst was removed from the 'cold' mixture. The yield of 83a was $13 \%$ in this step. The 'cold' clear solution was refluxed for $24 \mathrm{~h}$ (total time $30 \mathrm{~h}$ ) without $\{\mathrm{Pd}\}$ $\mathrm{S}-\mathrm{GaAs}$ to give $83 \mathrm{a}$ in $28 \%$ yield. In both cases, the product increased, even if the catalyst was removed from the reaction mixture. However, these chemical yields were much lower than that of the reaction in which $\{\mathrm{Pd}\}-\mathrm{S}-\mathrm{GaAs}$ was employed from the beginning to the end.

Considering that there is no relationship between chemical yield and amount of leached Pd (Figs. 2, 3) for the Heck reaction, these results indicate: 1) During the Heck reaction, a trace amount of Pd species was leached from $\{\mathrm{Pd}\}-\mathrm{S}-\mathrm{GaAs}$ into the reaction mixture. 2) The leached Pd species has some activity in the Heck reaction. 3) The catalytic activity of leached Pd is lower than that of $\{\mathrm{Pd}\}-\mathrm{S}-\mathrm{GaAs}$. 4) For a highly efficient Heck reaction, the presence of $\{\mathrm{Pd}\}-\mathrm{S}-\mathrm{GaAs}$ is critical, although we do not know if $\{\mathrm{Pd}\}-\mathrm{S}-\mathrm{GaAs}$ works as the actual active species or the pre-catalyst.
We have successfully developed a method for preparing $\{\mathrm{Pd}\}-\mathrm{S}-\mathrm{GaAs}(001)(\mathbf{B})$, the catalytic activity of which for the Heck reaction does not decrease after 10 uses and which shows only trace amounts of Pd leached into the reaction mixture after the 5th run. In addition, it was clear that the immobilized $\mathrm{Pd}$ on $\mathrm{S}-\mathrm{GaAs}(001)$ is $\mathrm{Pd}(0)$. This catalyst is easy to recover and transfer under air using a pair of tweezers. We hope that this catalyst might lead to new opportunities in environmentally benign immobilized catalysts and microreactors.

Acknowledgements Most of the results in this review were obtained at Chiba University, where I worked from April 1999 to October 2005. I would like to thank Prof. Masako Nakagawa (Chiba University, Kanagawa University) and Prof. Atsushi Nishida (Chiba University) for their continuous advice and support. I want to express my thanks to Prof. Yasuyuki Kita (Osaka University) and to Prof. Satoshi Shuto (Hokkaido University) for his continuous encouragement and understanding for my project at Hokkaido University, where I have been working since November, 2005. I also thank all of my coworkers, Prof. Shiro Tsukamoto (Anan National College of Technology), Dr. Masahiko Shimoda (National Institute of Material Sciences), postdoctoral fellows, graduate students and undergraduate students, Dr. Chumpol Theeraladaon, Dr. Yukiyoshi Terada, Dr. Masahiro Hamada, Dr Mohammad Gulam Rabbani, Mr. Hiroaki Kaneko, Mr. Kazuyuki Takahashi, Ms. Noriko Obitsu, Ms. Ikuko Takamiya, Mr. Naoki Miyashita, Mr. Dai Nagaki, Mr. Takayuki Watanabe, Ms. Maki Takahashi and Ms. Yuko Ando. I would like to thank Prof. Kazuo T. Suzuki and Prof. Yasumitsu Ogra (Chiba University) for performing the ICM-Mass experiments. I am indebted to Keyence Corporation for conducting the SEM experiments. This research was supported by an IT program and a Grant-in-Aid for Exploratory Research and the Encouragement of Young Scientists (A) from the Ministry of Education, Culture, Sports, Science and Technology, Japan. I am also grateful for financial support received from the Iketani Foundation, Yazaki Memorial Foundation for Science and Technology, the Fujisawa Foundataion, Mitsubishi Chemical Corporation Fund, a Takeda Chemical Industries Ltd. Award in Synthetic Organic Chemistry. and a Mitsui Chemical Ltd. Award in Synthetic Organic Chemistry.

\section{References}

1) For recent reviews of olefin metathesis, see: Connon S. J., Blechert S., Angew. Chem. Int. Ed., 42 1900-1923 (2003).

2) Deiters A., Martin S. F., Chem. Rev., 104, 2199-2238 (2004).

3) Grubbs R. H., Tetrahedron, 60, 7117-7140 (2004).

4) Armstrong S. K., Chem. Soc., Perkin Trans. 1, 1998, 371-388 (1998).

5) Schwab P., Grubbs R. H., Ziller J. W., J. Am. Chem. Soc., 118, 100110 (1996).

6) Schwab P., France M. B., Ziller J. W., Grubbs R. H., Angew. Chem. Int. Ed., 34, 2039-2041 (1995).

7) Scholl M., Trnka T. M., Morgan J. P., Grubbs R. H., Tetrahedron Lett., 40, 2247-2250 (1999).

8) Scholl M., Ding S., Lee C. W., Grubbs R. H., Org. Lett., 1, 953-956 (1999).

9) Chatterjee A. K., Grubbs R. H., Org. Lett., 1, 1751-1753 (1999).

10) Kingsbury J. S., Harrity J. P. A., Bonitatebus, P. J., Jr., Hoveyda A. H., J. Am. Chem. Soc., 121, 791-799 (1999).

11) Arisawa M., Takezawa E., Nishida A., Mori M., Nakagawa M., Synlett, 1997, 1179-1180 (1997).

12) Nakagawa M., Uchida H., Torisawa Y., Nishida A., J. Synth. Org Chem. Jpn., 57, 1004-1005 (1999).

13) Arisawa M., Kato C., Kaneko H., Nishida A., Nakagawa M., J. Chem. Soc. Perkin Trans. I, 2000, 1873-1876 (2000).

14) Arisawa M., Kaneko H., Nishida A., Yamaguchi K., Nakagawa M., Synlett, 2000, 841-843 (2000).

15) Arisawa M., Takahashi M., Takezawa E., Yamaguchi T., Torisawa Y., Nishida A., Nakagawa M., Chem. Pharm. Bull., 48, 1593-1596 (2000).

16) Arisawa M., Theeraladanon C., Nishida A., Nakagawa M., Tetrahedron Lett., 42, 8029-8033 (2001).

17) Arisawa M., Kaneko H., Nishida A., Nakagawa M., J. Chem. Soc. Perkin Trans. I, 2002, 959-964 (2002).

18) Arisawa M., Terada Y., Nakagawa M., Nishida A., Angew. Chem. Int. 
Ed., 41, 4732-4734 (2002).

19) Nagata T., Nakagawa M., Nishida A., J. Am. Chem. Soc., 125 , $7484-7485$ (2003).

20) Ono K., Nakagawa M., Nishida A., Angew. Chem. Int. Ed., 43, 2020-2023 (2004).

21) Theeraladanon C., Arisawa M., Nishida A., Nakagawa M., Tetrahedron, 60, 3017-3035 (2004)

22) Terada Y., Arisawa M., Nakagawa M., Nishida A., Angew. Chem. Int. Ed., 43, 4063-4067 (2004)

23) Terada Y., Arisawa M., Nishida A., Chemical Times, 194, 2-10 (2004).

24) Theeraladanon C., Arisawa M., Nakagawa M., Nishida A., Tetrahedron: Asymmetry, 16, 827-831 (2005).

25) Arisawa M., Terada Y., Theeraladanon C., Takahashi K., Nakagawa M., Nishida A., J. Organomet. Chem., 690, 5398-5406 (2005).

26) Arisawa M., Theeraladanon C., Nishida A., Heterocycles, 66, 683688 (2005).

27) Terada Y., Arisawa M., Nishida A., J. Org. Chem., 71, 1269-1272 (2006).

28) Arisawa M., Terada Y., Takahashi K., Nakagawa M., Nishida A., J. Org. Chem., 71, 4255-4261 (2006).

29) Arisawa M., Nishida A., Nakagawa M., J. Organomet. Chem., 691, 5109-5121 (2006).

30) Arisawa M., Terada Y., Takahashi K., Nakagawa M., Nishida A., The Chem. Record, 7, in press (2007).

31) Giannis A., Kolter T., Angew. Chem. Int. Ed. Engl., 32, 1244-1267 (1993).

32) Michael J. P., Nat. Prod. Rep., 16, 675-696 (1999).

33) Michael J. P., Nat. Prod. Rep., 15, 571-594 (1998).

34) Liddell J. R., Nat. Prod. Rep., 15, 363-370 (1998).

35) Paolucci C., Musiani L., Venturelli F., Fava A., Synthesis, 1997, 1415-1419 (1997).

36) Uchida H., Nishida A., Nakagawa M., Tetrahedron Lett., 40, 113 116 (1999).

37) Torisawa Y., Than S., Katoh C., Motohashi Y., Nishida A., Hino T., Nakagawa M., Heterocycles, 42, 655-659 (1998).

38) Torisawa Y., Hosaka T., Tanabe K., Suzuki N., Motohashi Y., Hino T., Nakagawa M., Tetrahedron, 52, 10597-10608 (1996).

39) Nakagawa M., Torisawa Y., Hosaka T., Tanabe K., Date T., Okamura K., Hino T., Tetrahedron Lett., 34, 4543-4546 (1993).

40) Torisawa Y., Nakagawa M., Hosaka T., Tanabe K., Lai Z., Ogata K., Nakata T., Ohishi T., Hino T., J. Org. Chem., 57, 5741—5747 (1992).

41) Tarling D. A., Holmes A. B., Markwell R. E., Pearson N. D., J. Chem. Soc., Perkin Trans. 1, 1999, 1695-1701 (1999).

42) Diedrichs N., Wetermann B., Synlett, 1999, 1127-1129 (1999).

43) Martin S. F., Humphrey J. M., Ali A., Hillier M. C., J. Am. Chem. Soc., 121, 866-867 (1999).

44) Pandit U. K., Overekleeft H. S., Borer B. C., Bieräugel H., Eur. J. Org. Chem., 1999, 959—968 (1999).

45) Grossmith C. E., Senia F., Wagner J., Synlett, 1999, 1660-1662 (1999).

46) Sakai R., Kohmoto S., Higa T., Jefford C. W., Bernardinelli G., Tetrahedron Lett., 28, 5493-5496 (1987).

47) Torisawa Y., Hashimoto A., Nakagawa M., Hino T., Tetrahedron Lett., 30, 6549-6550 (1989).

48) Torisawa Y., Hashimoto A., Nakagawa M., Seki H., Hara R., Hino T., Tetrahedron, 47, 8067-8078 (1991).

49) Nowak W., Gerlach H., Liebigs Ann. Chem., 1993, 153-159 (1993).

50) Vidal T., Magnier E., Langlois Y., Tetrahedron, 54, 5959-5966 (1998).

51) Torisawa Y., Hashimoto A., Okouchi M., Iimori T., Nagasawa M., Hino T., Nakagawa M., Bioorg. Med. Chem. Lett., 6, 2565-2570 (1996).

52) Sukkari H. E., Gesson J.-P., Renoux B., Tetrahedron Lett., 39, 40434046 (1998).

53) Nishida A., Yamanaka M., Nakagawa M., Tetrahedron Lett., 40, 1555 -1558 (1999).

54) Alkene metathesis; macrolactams: Fürstner A., Dierkes T., Thiel O. R., Blanda G., Chem. Eur. J., 7, 5286-5298 (2001).

55) Fürstner A., Thiel O. R., Ackermann L., Org. Lett., 3, 449-451 (2001).

56) Fürstner A., Thiel O. R., Kindler N., Bartkowska B., J. Org. Chem., 65, 7990-7995 (2000)

57) Lee C. W., Grubbs R. H., Org. Lett., 2, 2145-2147 (2000).
58) Fürstner A., Thiel O. R., Blanda G., Org. Lett., 2, 3731-3734 (2000).

59) Goldring W. P. D., Hodder A. S., Weiler L., Tetrahedron Lett., 39, 4955-4958 (1998).

60) Fürstner A., Langemann K., Synthesis, 1997, 792-803 (1997).

61) Fürstner A., Langemann K., J. Org. Chem., 61, 3942-3943 (1996).

62) Alkyne metathesis; Fürstner A., Mathes C., Lehmann C. W., Chem. Eur. J., 7, 5299-5317 (2001)

63) Fürstner A., Guth O., Rumbo A., Seidel G., J. Am. Chem. Soc., 121 11108 - 11113 (1999).

64) Fürstner A., Seidel G., Angew. Chem. Int. Ed., 37, 1734-1736 (1998).

65) Jin S. J., Tserng K. Y., Biochemistry, 29, 8540-8547 (1990).

66) For examples, ruthenium-catalyzed versions; Tsuji Y., Huh K. T., Watanabe Y., J. Org. Chem., 52, $1673-1680$ (1987).

67) Cho C. S., Oh B. H., Kim J. S., Kim T.-J., Shim S. C., Chem. Commun., 2000, 1885-1886 (2000).

68) Evans P. A., Robinson J. E., Moffett K. K., Org. Lett., 3, 3269-3271 (2001).

69) Palladium-catalyzed versions; Cortese N. A., Ziegler C. B., Hrnjez B J., Heck R. F., J. Org. Chem., 43, $2952-2958$ (1978).

70) Hegedus L. S., Allen G. F., Bozell J. J., Waterman E. L., J. Am. Chem. Soc., 100, 5800-5807 (1978).

71) Laborde E., Lesheski L. E., Kiely J. S., Tetrahedron Lett., 31, 1837 1840 (1990).

72) Larock R. C., Kuo M. Y., Tetrahedron Lett., 32, 569-572 (1971).

73) Kundu N. G., Mahanty J. S., Das P., Das B., Tetrahedron Lett., 34 $1625-1628$ (1993).

74) Dupont J., Halfen R. A. P., Zinn F. K., Pfeffer M., J. Organomet. Chem., 484, c8-c9 (1994).

75) Cacchi S., Fabrizi G., Marinelli F., Synlett, 1999, 401- 404 (1999).

76) Pita B., Masaguer C. F., Ravina E., Tetrahedron Lett., 43, 7929 7932 (2002).

77) Hatano M., Mikami K., J. Am. Chem. Soc., 125, 4704-4705 (2003).

78) Rhodium-catalyzed versions; Diamond S. E., Szalkiewicz A., Mares F., J. Am. Chem. Soc., 101, 490-491 (1979).

79) Watanabe Y., Yamamoto M., Shim S. C., Mitsudo T., Takegami Y., Chem. Lett., 1979, 1025-1026 (1979).

80) Watanabe Y., Suzuki N., Shim S. C., Yamamoto M., Mitsudo T. Takegami Y., Chem. Lett., 1980, 429-430 (1980).

81) Boyle W. J., Mares F., Organometallics, 1, 1003-1006 (1982).

82) Amii H., Kishikawa Y., Uneyama K., Org. Lett., 3, 1109-1112 (2001).

83) Iron-catalyzed version; Watanabe Y., Takatsuki K., Shim S. C., Mitsudo T., Takegami Y., Bull. Chem. Soc. Jpn., 51, 3397-3398 (1978).

84) Copper-catalyzed version; Huma H. Z. S., Halder R., Kalra S. S., Das J., Iqbal J., Tetrahedron Lett., 43, 6485-6488 (2002).

85) Manganese-catalyzed version; Kobayashi K., Nakahashi R., Mano M., Morikawa O., Konishi H., Bull. Chem. Soc. Jpn., 76, 1257-1259 (2003).

86) Cobalt-catalyzed version; Domínguez G., Casarrubios L., RodríguezNoriega J., Pérez-Castells J., Helv. Chim. Acta, 85, 2856-2861 (2002).

87) Nishida A., Sorimachi H., Iwaida M., Matsumizu M., Kawate T. Nakagawa M., Synlett, 1998, 389-390 (1998).

88) Turner R. B., Woodward R. B., “The Alkaloids,” Vol. 3, Chap. 16, ed. by Manske R. H. F., Academic Press, New York, 1953, pp. 1-63.

89) Uskokoviac M. R., Grethe G., "The Alkaloids," Vol. 14, ed. by Manske R. H. F., Academic Press, New York, 1973, pp. 181-223.

90) Grethe G., Uskokovic M. R., "The Chemistry of Heterocyclic Compounds," Vol. 23, Part 4, ed. by Sexton J. E., Wiley-Interscience, New York, 1983, p. 279.

91) Dutta N. L., Quassim C., Indian J. Chem., 6, 566-567 (1968).

92) For stereoselective total synthesis: Stork G., Niu D., Fujimoto A., Koft E. R., Balkovec J. M., Tata J. R., Dake G. R., J. Am. Chem. Soc., 123, 3239-3242 (2001).

93) Andersag H., Breitner S., Jung H., German Patent 683692 (1939) [Chem. Abstr., 36, 4973 (1942)].

94) Andersag H., Breitner S., Jung H., US Patent 2233970 (1941) [Chem. Abstr., 35, 3771 (1941)].

95) Jacquemond-Collet I., Hannedouche S., Fabre N., Fourste I., Phytochemistry, 51, 1167-1169 (1999).

96) Rakotoson J. H., Fabre N., Jacquemond-Collet I., Hannedouche S., 
Fourste I., Moulis C., Planta Med., 64, 762-763 (1998).

97) Mester I., Fitoterapia, 44, 123-152 (1973).

98) Houghton P. J., Woldemariam T. Z., Watanabe T., Yates M., Planta Med., 65, 250-254 (1999).

99) Jacquemond-Collet I., Benoit-Vical F., Mustofa, Valentin A., Stanislas E., Mallie M., Planta Med., 68, 68-69 (2002).

100) Wang W., Lu S., Yang P., Han X., Zhou Y., J. Am. Chem. Soc., 125, 10536-10537 (2003)

101) Mitsunobu O., Synthesis, 1981, 1-28 (1981).

102) Kadnikov D. V., Larock R. C., J. Org. Chem., 69, 6772-6780 (2004).

103) Nagata T., Koide Y., Nara K., Itoh E., Arisawa M., Naruto S., Torisawa Y., Hino T., Nakagawa M., Chem. Pharm. Bull., 44, 451-453 (1996).

104) Nakamura I., Yamamoto Y., Chem. Rev., 104, 2127 -2198 (2004).

105) Boger D. L., Ishizaki T., Wysocki R. J., Jr., Munk S. A., J. Am. Chem. Soc., 111, 6461-6463 (1989).

106) Sakamoto T., Kondo Y., Uchiyama M., Yamanaka H., J. Chem. Soc., Perkin Trans. 1, 1993, 1941-1942 (1993).

107) Yamanaka M., Nishida A., Nakagawa M., J. Org. Chem., 68, 31123120 (2003)

108) Ferraris D., Young B., Cox C., Dudding T., Drury W. J., III, Ryzhkov L., Taggi A. E., Lectka T., J. Am. Chem. Soc., 124, 67-77 (2002).

109) Burke M. D., Schreiber S. L., Angew. Chem. Int. Ed., 43, 46-58 (2004).

110) Dinger M. B., Mol J. C., Eur. J. Inorg. Chem., 2003, 2827-2833 (2003).

111) Louie J., Grubbs R. H., Organometallics, 21, 2153-2164 (2002).

112) Phay N., Higashiyama T., Tsuji M., Matsuura H., Fukushi Y., Yokota A., Tomita F., Phytochemistry, 52, 271-274 (1999).

113) For a review of biologically active compounds in onions, see: Griffiths G., Trueman L., Crowther T., Thomas B., Smith B., Phytother Res., 16, 603-615 (2002).

114) Tada M., Hiroe Y., Kiyohara S., Suzuki S., Agric. Biol. Chem., 52, $2383-2385$ (1988)

115) Wakamatsu H., Nishida M., Adachi N., Mori M., J. Org. Chem., 65, 3966-3970 (2000).

116) van Otterlo W. A. L., Ngidi E. L., de Koning C. B., Tetrahedron Lett., 44, 6483-6486 (2003).

117) van Otterlo W. A. L., Pathak R., de Koning C. B., Synlett, 2003, 1859-1861 (2003).

118) van Otterlo W. A. L., Morgans G. L., Khanye S. D., Aderibigbe B. A. A., Michael J. P., Billing D. G., Tetrahedron Lett., 45, 9171—9175 (2004).

119) Hirokawa Y., Harada H., Yoshikawa T., Yoshida N., Kato S., Chem. Pharm. Bull., 50, 941—959 (2002).

120) For 3-hydroxyindoles, see: Capon B., Kwok F.-C., J. Am. Chem. Soc., 111, 5346-5356 (1989).

121) Hickman Z. L., Sturino C. F., Lachance N., Tetrahedron Lett., 41, $8217-8220(2000)$

122) Kirby G. W., Shah S. W., Chem. Commun., 1965, 381a (1965).

123) Huang A., Kodanko J. J., Overman L. E., J. Am. Chem. Soc., 126, 14043-14053 (2004)

124) Negishi E., "Handbook of Organopalladium Chemistry for Organic Synthesis," Wiley Interscience, New York, 2002.
125) Tsuji J., "Palladium Reagents and Catalysts," Wiley, Chichester 2004.

126) Beletskaya I. P., Cheprakov A. V., Chem. Rev., 100, 3009-3066 (2000).

127) Biggis A., Zecca M., Basato M., J. Mol. Catal. A, 173, 249-274 (2001).

128) Fan Q.-H., Li Y.-M., Chan A. S. C., Chem. Rev., 102, 3385-3466 (2002).

129) Leadbeater N. E., Marco M., Chem. Rev., 102, 3217-3274 (2002).

130) Song C. E., Lee S.-G., Chem. Rev., 102, 3495-3524 (2002).

131) Dupont J., de Souza R. F., Auarez P. A. Z., Chem. Rev., 102, $3667-$ $3692(2002)$

132) Kobayashi J., Mori Y., Okamoto K., Akiyama R., Ueno M., Kitamori T., Kobayashi S., Science, 304, 1305-1308 (2005).

133) Ji Y., Jain S., Davis R. J., J. Phys. Chem. B, 109, 17232-17238 (2005).

134) Zhao F., Shirai M., Lkushima Y., Arai M., J. Mol. Catal. A: Chem., 180, 211-219 (2002).

135) Arisawa M., Tsukamoto S., Shimoda M., Pristovsek M., Nishida A., Jpn. J. Appl. Phys., 41, L1197-L1199 (2002).

136) Takamiya I., Tsukamoto S., Shimoda M., Miyashita N., Arisawa M., Arakawa Y., Nishida A., Chem. Lett., 33, 1208-1209 (2004).

137) Herrmann W. A., Brossmer C., Öfele K., Beller M., Fisher H., J. Mol Catal. A: Chem., 103,133-146 (1995).

138) Beller M., Fisher H., Kühlein K., Reisinger C. P., Herrman W. A., $J$ Organomet. Chem., 520, 257-259 (1996).

139) Djakovitch L., Koehler K., J. Am. Chem. Soc., 123, 5990-5999 (2001).

140) Gruber M., Chouzier S., Koehler K., Djakovitch L., Appl. Catal. A. General, 265, 161-169 (2004).

141) Xiong Z., Wang N., Dai M., Li A., Chen J., Yang Z., Org. Lett., 6 , 3337 -3340 (2004)

142) Reactivity of methyl vinyl ketone is usually lower than that of methyl acrylate. $76 \%$ of chemical yield is useful in literatures: Botella $\mathrm{L}$., Nájera C., J. Org. Chem., 70, 4360-4369 (2005).

143) Botella L., Nájera C., Tetrahedron Lett., 45, 1833-1836 (2004).

144) Yang D., Chen Y.-C., Zhu N.-Y., Org. Lett., 6, 1577-1580 (2004).

145) Cacchi S., Fabrizi G., Goggiamani A., Arkivoc, 2003, 58 - 66 (2003).

146) Hagiwara H., Shimizu Y., Hoshi T., Suzuki T., Ando M., Ohkubo K., Yokoyama C., Tetrahedron Lett., 42, 4349— 4351 (2001).

147) Clark J. H., Macquarrie D. J., Mubofu E. B., Green Chem., 2, 53-56 (2000).

148) Cacchi S., Fabrizi G., Gasparrini F., Villani C., Synlett, 1999, 345347 (1999).

149) Shimoda M., Tsukamoto S., Koguchi N., Surf. Sci., 402, 669-672 (1998).

150) The palladium(II) $3 \mathrm{~d} 5 / 2$ peak from $\mathrm{PdCl}_{2}$ is observed at $338.3 \mathrm{eV}$.

151) Rebek J., Gavina F., J. Am. Chem. Soc., 96, 7112-7114 (1974).

152) Rebek J., Brown D., Zimmerman S., J. Am. Chem. Soc., 97, 454 455 (1975).

153) Davies I. A., Matty L., Hughes D. L., Reider P. J., J. Am. Chem. Soc., 123, 10139-10140 (2001).

154) Baleizao C., Corma A., Garcia H., Leyva A., J. Org. Chem., 69, $439-446$ (2004). 